\title{
Environmental modelling of building stocks - An integrated review of life cycle-based assessment models to support EU policy making
}

\author{
Martin Röck $^{\mathrm{a}, \mathrm{b},{ }^{*}, \text { Elena Baldereschi }}{ }^{\mathrm{a}, \mathrm{c}}$, Evelien Verellen ${ }^{\mathrm{a}}$, Alexander Passer ${ }^{\mathrm{b}}$, Serenella Sala ${ }^{\mathrm{c}}$, \\ Karen Allacker ${ }^{\text {a }}$
}

${ }^{\text {a }}$ KU Leuven, Faculty of Engineering Science, Department of Architecture, Leuven, BE, Belgium

${ }^{\mathrm{b}}$ Graz University of Technology, Working Group Sustainable Construction, Graz, AT, Austria

${ }^{\mathrm{c}}$ European Commission, Joint Research Centre, Ispra, IT, Italy

\section{A R T I C L E I N F O}

\section{Keywords:}

Life cycle assessment (LCA)

Built environment

Spatial and temporal dynamics

Scenario analysis

Environmental impacts

Embodied impacts

Embodied carbon

Material flow analysis

Mitigation

Adaptation

Life cycle analysis

Environmental policy

Policy support

European green deal

Renovation wave

Energy retrofit

Systematic literature review

\begin{abstract}
A B S T R A C T
Various environmental challenges, particularly the rising severity of the impacts of climate change, require a systematic shift in and decarbonization of the global economy. Due to their high environmental impacts, buildings and construction have a special role in decarbonization. Environmental modelling of building stock dynamics can help policy makers and inform decision making.

This study presents a systematic review of both the latest scientific literature on environmental modelling of building stocks and related EU policy initiatives. Our findings illuminate the strengths and limitations of existing approaches as well as the potential of such modelling and the required directions for future development to provide effective policy support.

Based on the assessment of 104 scientific papers, our study shortlisted and analysed 22 environmental building stock modelling approaches. While promising, these show various limitations on their effectiveness in supporting decarbonization efforts while avoiding burden shifting. Future building stock models should offer extended system boundaries and comprehensive life cycle assessment, improved hotspot analysis and impact monitoring across spatiotemporal scales. A long-term perspective on the entire building stock covering climate and other environmental impacts is needed, as outlined in the latest standards. By linking existing studies to related EU policy objectives, we identify various studies that investigate scenarios and strategies relevant to EU policy makers and highlight research gaps.

Future research should enable comprehensive environmental assessment of building stocks across scales and emphasize the monitoring of multiple environmental impacts of building stock development to ensure compliance with environmental targets and minimization of trade-offs.
\end{abstract}

\section{Introduction}

As the severe effects of climate and ecological crises are increasingly felt across the globe, the need to rapidly depollute and decarbonize the world economy is becoming urgent. For effective climate change mitigation, a systemic approach is needed, focusing on defining sustainable solutions to reduce key drivers of impacts while avoiding trade-offs [1]. Systemic approaches have to evolve from simply assessing improvements in relative efficiency towards addressing sustainability from an absolute perspective, i.e., ensuring that development occurs within environmental boundaries [2]. Recent developments such as the COVID-19 pandemic highlight the need to rethink the role of humans in

Abbreviations: AP, Acidification potential; ADP, Abiotic depletion potential; BIM, Building information modelling; BIPV, Building integrated photovoltaics; BSA,

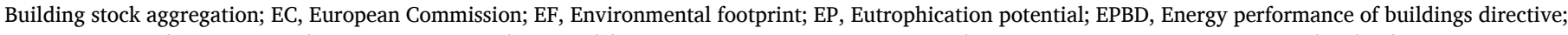

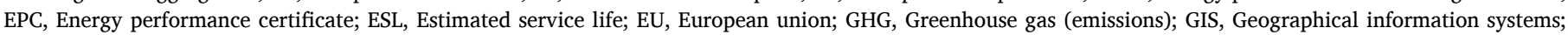

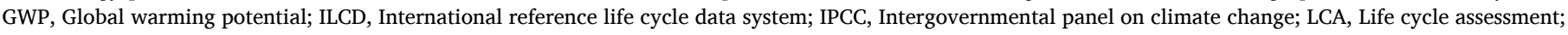

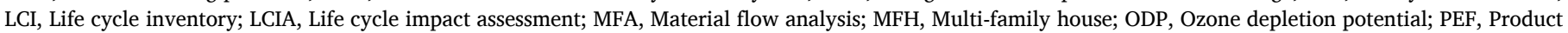

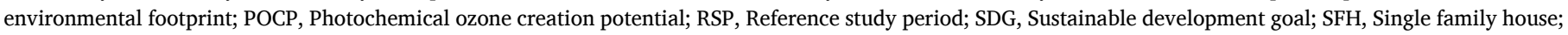
SLR, Systematic literature review.

* Corresponding author. Graz University of Technology, Working Group Sustainable Construction, Graz, AT, Austria.

E-mail addresses: martin.roeck@tugraz.at (M. Röck), karen.allacker@kuleuven.be (K. Allacker). 
the planetary ecosystem and to maximize the potential of a green stimulus within the global economy.

Building construction and operations are crucial to the success of efforts to limit climate change, as they account for approximately $40 \%$ of global greenhouse gas (GHG) emissions [3] and are among the key contributors to the environmental impacts of consumption in Europe [4, 5]. The built environment is at the heart of the sustainability transformations envisaged under the Sustainable Development Goals (SDGs). Various proposals for quantifying environmental targets related to buildings and construction have been put forward. Such targets, e.g., GHG emission budgets, have been calculated for several countries with the aim of harmonizing spatial, temporal and sectoral target definitions across scales [6]. While a reduction in GHG emissions related to building operations has been achieved in recent years due to stricter energy-efficiency regulations, so-called embodied GHG emissions have increased in both relative and absolute terms [7]. Considering that an additional 26 million $\mathrm{m}^{2}$ of buildings are to be constructed and operated in Europe by 2050 [8], it is of overarching importance to optimize and reduce GHG emissions related to building operation and construction to enable effective climate change mitigation. However, in developed regions of the Global North such as in the European Union (EU), most buildings that will be standing in 2050 have already been built and are in use today. Hence, enabling renovations and energy-efficiency improvements of the existing building stock is recognized as a crucial challenge.

The EU is a global leader in both climate ambition and action. The various environmental policies launched within the so-called EU Green Deal are amongst the most ambitious in the world, calling for reductions of GHG emissions in the EU economy of 55-60\% from 1990 levels by $2030 .{ }^{1}$ Various policy initiatives acknowledge the importance of the built environment regarding both the operation of buildings and their production and construction. The "renovation wave", which aims at increasing yearly renovation rates to at least double, is touted as one of the main initiatives for reducing EU GHG emissions and stimulating green investment. This renovation wave and the recent call for a "New European Bauhaus" represent key institutional efforts to support the implementation of ambitious EU policies on building construction and operation. The effective implementation of these initiatives depends on the deployment of suitable methods and tools to support environmental modelling, monitoring and management of the EU building stock.

To inform policy makers and other decision makers on the environmental implications of decisions, the life cycle assessment (LCA) method is increasingly applied. The general application of LCA is internationally standardised (ISO 14040) with several standards in the EU context defining the specifics of its application, e.g., to assess construction products (EN 15804) or buildings (EN 15978). Recent studies have highlighted the role and increasing importance of LCA in EU policymaking [9]. Furthermore, LCA is listed as a tool for policy support in the Better Regulation Toolbox, an EU initiative aiming at improving the policy process. The use of LCA is foreseen in different steps of the EU policy cycle, as outlined in Fig. 1. LCA use cases range from supporting the policy anticipation and problem definition (identification of issues for which a policy intervention is needed), up to policy impact assessment (comparing different policy options) as well as policy implementation and assessment of policy effectiveness.

To develop and identify effective policies to reduce building-related GHG emissions and other environmental impacts, not only the modelling and assessment of individual buildings but also a move to the system level are required, taking into account the characteristics and dynamics of building stocks at scale. Several research projects have focused on methodological questions surrounding building stock modelling - primarily utilized for modelling building-related energy use - and its

\footnotetext{
${ }^{1}$ EC, COM/2020/562 final, Stepping up Europe's 2030 climate ambition Investing in a climate-neutral future for the benefit of our people, 2020.
}

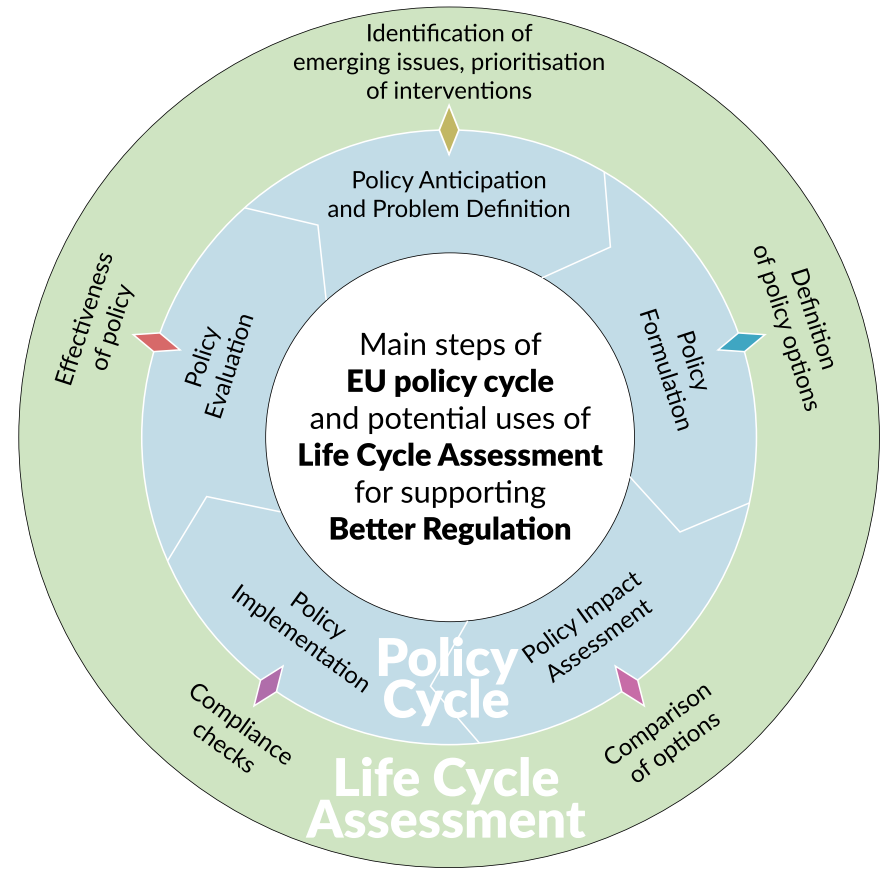

Fig. 1. Main steps of the EU policy cycle and the potential uses of Life Cycle Assessment to support Better Regulation (adopted from Ref. [10]).

practical implications. In 2004, as one of the results of the International Energy Agency's (IEA's) Energy in Buildings and Communities Programme (EBC) Annex 31 on "Energy-Related Environmental Impact of Buildings", Moffatt et al. [11] proposed a conceptual framework with modules relevant to bottom-up building stock aggregation models from an energy modelling perspective. The proposed concept is still relevant and has frequently been adopted in contemporary studies, the scope of which has increasingly been extended to achieve more holistic environmental modelling of building stocks and related dynamics. In 2017, Mastrucci et al. [12] presented a comprehensive review on the topic, including a categorization of stock modelling approaches ranging from the urban to the transnational scale. The study covered papers published from 2006 to 2015. More recently, in 2019, Göswein et al. [13] presented a review on environmental modelling of urban building stocks, focusing on the modelling of spatial and temporal dynamics and the combination of both. While their study focused on the urban scale, it provided valuable findings on modelling and method-related differences and proposed a framework for identifying suitable approaches to providing insights to the different stakeholders concerned, amongst them policy makers.

\section{Objective and research questions}

The objective of this study is to review the latest research on the environmental modelling of building stocks and provide insights into the potential of and requirements for environmental modelling of building stocks to be used to support EU policy making. This study addresses two main research questions:

1) What is state of the art regarding methods for modelling and assessing environmental impacts of building stocks and related spatial and temporal dynamics?

2) What are the EU policy objectives related to building stock development and to what degree are existing modelling approaches suitable for supporting the assessment and implementation of these objectives?

To answer these questions, we conduct a systematic review of 
scientific literature from an LCA perspective to ensure a holistic approach in addressing building-related environmental impacts. This review focuses on the spatiotemporal scope of assessment methods, data sources, and tools and software and critically evaluates the comprehensiveness and performance of environmental hotspot analysis across spatiotemporal dimensions. We include an in-depth review and analysis of methodological aspects and databases, model-related characteristics such as data granularity and data sources and an analysis of the presentation of results and their critical evaluation within studies. Furthermore, we link the findings on building stock modelling approaches to the relevant EU policy objectives to identify the potential of and requirements for the implementation of these approaches as well as research needs from a policy support perspective.

The novelty of this study stems from its integrated analysis of scientific literature and policy objectives. This paper aims to make a considerable advance on the analyses in previous studies by linking the findings to EU policy objectives to provide insights into the potential of and need for policy-making support through environmental modelling of building stocks and related dynamics.

\section{Material and methods}

This study addresses the research questions in three main steps, as shown in Fig. 2:

1) An analysis of relevant EU policies to identify policy objectives related to building stock development, building construction and operation;

2) A systematic review and analysis of the scientific literature to identify the state of the art of environmental modelling of building stock dynamics from an LCA perspective; and

3) A synthesis of the findings from the scientific literature in relation to EU policy objectives and discussion of the potential of environmental modelling of building stocks to support EU policy and the directions in which such approaches should be developed for this purpose, as well as gaps in the research related to EU policy.

Sections 3.1. and 3.2. Provide details on the method adopted for the review of policy documents and the scientific literature, respectively.

\subsection{Review of EU policy documents}

To analyse EU policy initiatives related to buildings and construction, we reviewed various relevant policy documents issued by the European Commission (EC) in recent years. We identified and reviewed documents related to the following policy initiatives referring directly or indirectly to buildings and construction (full references are provided in the table of policy documents at the end of this paper):

- European Green Deal

- Circular Economy Action Plan (2020)

- Biodiversity Strategy for 2030

- European Climate Law

- EU Renovation Wave

- New Industrial Strategy

- A Clean Planet for All

- Bioeconomy Strategy

- EU Sustainable Development Goals (SDGs)

- Waste Framework Directive

We screened these documents and searched them for keywords related to environmental assessment of building stocks and building construction and operations. We collected relevant paragraphs and topics from the documents and synthesized these into a set of policy objectives relevant to EU building stock development and building construction and operations.

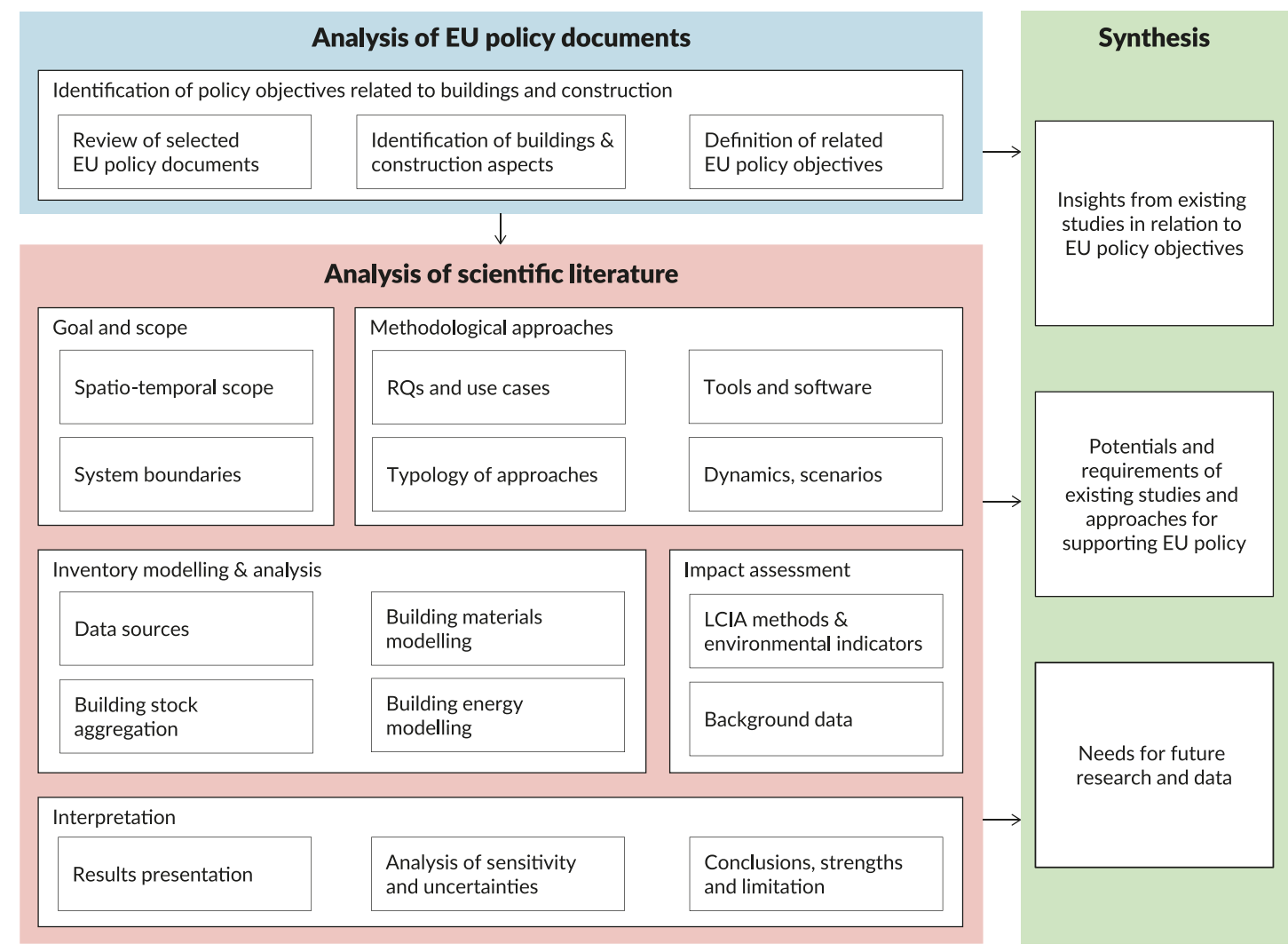

Fig. 2. Outline of the three main steps in this study: 1) analysis of EU policy documents; 2) analysis of the scientific literature; and 3) synthesis of the findings to identify the potential and requirements of such modelling to provide enhanced policy support. 


\subsection{Review of scientific literature}

We conducted a systematic literature review (SLR) to identify the state of the art of the published scientific literature [14,15]. Based on the research questions, search keywords were defined for use in the Scopus and ScienceDirect scientific databases; the searches covered article titles, abstracts and author-specified keywords. The search string, defined through an iterative process, was [(LCA OR life cycle analysis OR life cycle assessment) AND (building stock)]. We limited the results by article type to research articles and review articles (i.e., we excluded conference proceedings, books, theses, etc.). We considered studies whose year of publication was from 2016 to 2020 to build on the related 2017 review of Mastrucci et al. [12], which included studies up until 2015. We conducted the database search in May 2020.

Following a step-by-step process in line with the SLR protocol, we refined the initial search results by including only those studies fulfilling the following four criteria:

- Analysing a building stock using a bottom-up or hybrid (bottom-up and top-down) approach;

- Applying a life cycle-based approach for assessing operational and/ or embodied impacts;

- Focusing on building stocks at the urban to transnational scales (including national or regional scales); and

- Assessing at least one environmental indicator (i.e., material and energy flow studies without an environmental impact assessment were excluded).

A total of 104 unique papers were identified and then filtered in terms of relevance in three steps by screening their title, abstract and full text. After these screening and exclusion steps, 22 papers were identified as the final sample [16-37] for systematic data extraction and analysis. A flowchart of the SLR, data extraction and analysis is provided in Supplementary Information Figure S1.

Based on the final sample of studies, we conducted systematic data extraction, documenting information related to various pre-defined features and aspects, focusing on LCA-related dimensions. The relevant features were defined based on findings in the literature and following guidelines and standards related to environmental footprint assessment (EF guidelines) and LCA (ISO 14044) of construction products (EN 15804) and buildings (EN 15978). The feature groups defined for the data extraction process are presented in Supplementary Information Table S1. The final sample of studies is presented in Supplementary Information Table S2.

\section{Results of the analysis of EU policy documents}

\subsection{Policies initiatives underpinning the european Green Deal}

The reviewed policy documents relate to a set of policy initiatives for developing a sustainable, climate-neutral, circular and bio-based economy in the EU. Several of these policy initiatives have been developed under the umbrella of the European Green Deal, which sets the EC's priorities for the period 2019-24. In brief, the policies aim to support the decoupling of economic growth from resource use; enable the incremental implementation of the net-zero GHG emissions target by 2050, with intermediate goals for 2030; and ensure that people and regions are involved and not left behind in this transition. Each of the policy documents adds a piece of the puzzle by outlining specific targets and strategies for their specific field of action and related stakeholders. An extended summary of relevant points identified in each policy document is provided in Supplementary Results: Analysis of EU Policy Documents.

\subsection{EU policy objectives for building construction and operation}

Based on the document review and synthesis, we defined five policy objectives related to EU building stock development and building construction and operations:

1. Improvements to energy efficiency: Following up on the previous success of EU energy efficiency policies for buildings, such as the Energy Performance in Buildings Directives (EPBD), this objective focuses on further improving the energy operational efficiency of both existing and new buildings. For existing buildings, emphasis is placed on increasing renovation rates to at least double the current rates, i.e., to $\sim 3 \%$ per year, through the so-called renovation wave. 2. Increases in renewable energy: This objective describes the EU's ambition to increase renewable energy production to ensure lowcarbon energy provision as the backbone of the European lowcarbon economy. This entails an overall increase in the share of renewables in the EU energy and electricity mix as well as renewable energy production on site (e.g., building-integrated photovoltaics). 3. Circularity and low-carbon material uptake: This objective involves fostering the uptake of low-carbon construction materials, e. g., by increasing the use of bio-based materials and applying circularity principles through reuse and recycling. This objective also relates to efforts to reduce construction waste and the overall ambition of enabling a European circular bioeconomy.

4. Climate change adaptation and resilience: Enabling and enhancing climate change adaptation of EU buildings is crucial for improving resilience with an eye towards future changes in functional requirements. This objective covers efforts to support adaptable building design in anticipation of future changes in building use as

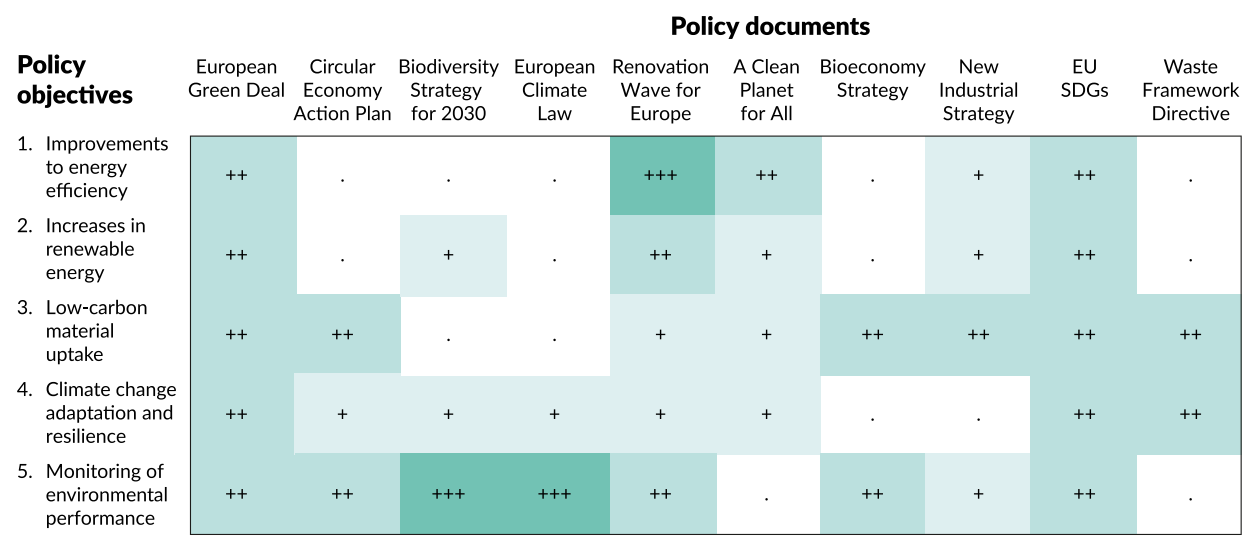

Fig. 3. Mapping of reviewed EU policy documents with defined policy objectives, highlighting their focus. 


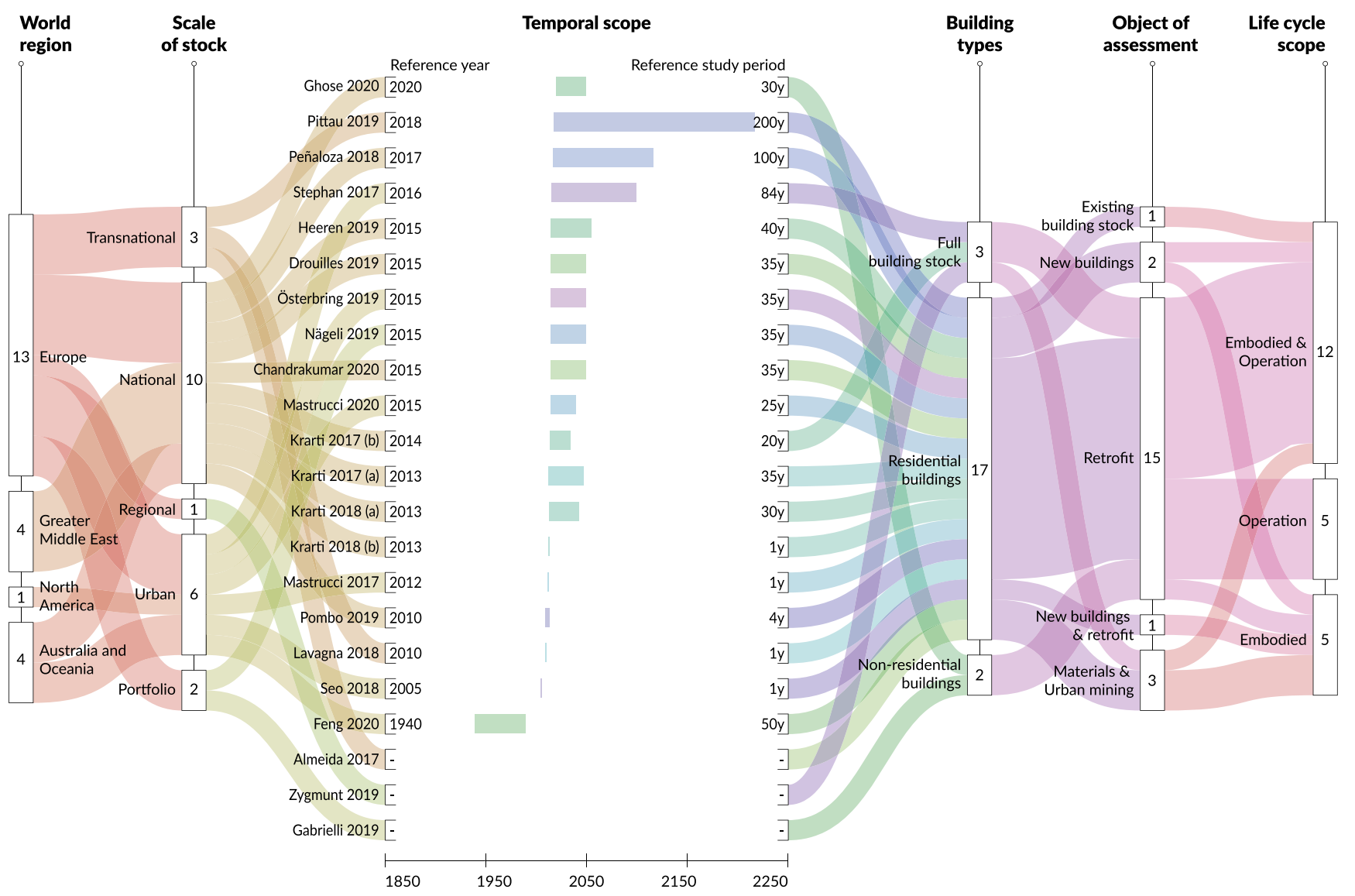

Fig. 4. Spatial and temporal scope of building stock modelling in the investigated studies.

well as in external conditions, e.g., due to climate change, for both existing and new buildings.

5. Monitoring of environmental performance: This objective aims to ensure the implementation of the EU's environmental targets through the assessment of environmental impacts over time, with special attention to ecosystem management, land use and land use change. For buildings, this involves monitoring the environmental performance of buildings throughout their life cycle to ensure compliance with environmental targets and the SDGs.

In Fig. 3, we provide a visual mapping of the reviewed EU policy documents and their focus in relation to these five policy objectives.

\section{Results of the analysis of scientific literature}

\subsection{Goal and scope of studies}

The results of the analysis of the goal and scope of the investigated studies are presented in the subsequent paragraphs, focusing on spatial and temporal aspects. The understanding of spatial and temporal dynamics related to the evolution of building stocks builds on the research presented by Mastrucci et al. [12] and Göswein et al. [13] in their respective reviews. In our analysis, we differentiate modelling of the building stock and modelling at the building level. Building stock modelling is conducted at the scale of the investigated building stock, with the relevant timeframe of the study and information on building types considered in the model, whereas building information modelling relates to the building life cycle and parts and the energy end uses considered. In line with the European standard for environmental life cycle assessment of construction products and buildings (EN 15804, EN 15978), we documented the consideration of life cycle stages and their respective modules, namely: the product stage (modules A1-A3); the construction process stage (A4, A5); the use stage, differentiated into modules related to embodied impacts (B1-B5) and impacts from operational energy and water use (B6, B7); and the end-of-life stage (C1-C4). We also documented the handling of benefits and loads outside the system boundary (module D), as these are related to end-of-life recycling and potential reuse.

Fig. 4 provides an overview of the spatial and temporal scope of the building stocks analysed in the investigated studies. We found that the majority of the studies in our final sample (13 of 22) investigate building stocks in a European context. Other regional contexts found are Australia and Oceania (4), the Greater Middle East (4) and North America (1). Most studies in our final sample investigate building stocks at a national scale (10), although the scale of building stocks studied ranges from the transnational (3) to the regional (1), urban (6) and portfolio scales (2). In terms of temporal scope, i.e., the timeframe of the study, most studies focus on prospective analyses and study building stock development and related environmental impacts based on stock development projections for several years, decades, or sometimes centuries into the future. Ten out of the 22 studies use a timeframe between 2013 and 2055 with a building stock reference study period (RSP) ranging from 25 to 40 years. Three studies deploy an extended timeframe of 84-200 years, taking 2016 to 2018 as their starting points. Five studies offer a snapshot of the state of the building stock in 1-4 specific years, with 2005-2013 as the reference years. The types of buildings investigated in the studies are mostly residential buildings (17 of 22), with two of these studies specializing in single-family houses (SFHs) and one on multi-family houses (MFHs). Two studies focus on other building types, such as office or university buildings. Three studies assess a full building stock covering various building types, including and beyond residential and office buildings. The majority of the studies focus on the 
retrofitting of existing buildings (15), taking different building types into consideration. Twelve out of the 22 studies in our sample take a life cycle approach to investigating both embodied and operational environmental impacts, while a total of ten studies focus exclusively on either embodied (5) or operational (5) impacts. While we documented the consideration of all life cycle stages and modules as defined in EN 15978, we here present the two general categories: embodied, i.e., material-related, impacts and operational impacts, i.e., those related to building energy and water use. The comprehensive analysis of the life cycle scope of the studies is presented in Supplementary Information Table S3.

Upon analysing the individual studies shown in Fig. 4, we found that the studies mainly investigate prospective timeframes of 25-35 years, i. e., reaching up to (or close to) 2050 and hence enabling an assessment of environmental targets and mitigation pathways up to mid-century. Only few studies project further into the future. Pittau et al. [34] apply an extensive temporal scope of 200 years to study refurbishment strategies for the European residential building stock with bio-based materials. Their study projects embodied GHG emissions as well as potential carbon storage from the use of different conventional and bio-based materials for a timeframe of 2018 until 2217. Pénaloza et al. [23] and Stephan and Athanassiadis [30] deploy timeframes of 100 and 84 years, respectively. Some studies analyse environmental impacts related to the building stock in a given year, e.g., the life cycle-based environmental impacts of the European building stock in 2010 [22]. One study conducts a retrospective analysis of the environmental impacts of building stocks in the 20th century based on the timeframe of 1940-1990 in a region of Canada [17]. In other cases, the expected environmental impacts of end-of-life treatment of materials are investigated for an urban building stock in Luxembourg (reference year 2012) [29] and Australia (reference year 2005) [24]. For three studies, we were unable to clearly identify the reference year and/or the duration. Additional information and details on the spatial and temporal scope of the individual studies together with a characterization of their modelling approaches are presented in the following sections and available in the Supplementary Data file.

The analysis of the spatial and temporal scope at the building level, i. e., life cycle stages, building parts and energy end uses considered in the different studies, revealed that none of the studies provide a complete assessment covering all these aspects in a comprehensive manner. Only two studies cover the full building life cycle, i.e., cradle to grave, without limitations [36,22]. Six studies approach a cradle-to-grave scope but show limitations due to the exclusion of some life cycle modules. The remaining studies have different scopes, with some focusing on cradle-to-gate or cradle-to-site, in-use or end-of-use life cycle modules. In the case of four studies, we could not clearly identify the life cycle stages covered from the documentation provided in the papers. An overview of the temporal scope regarding life cycle modules considered in the individual studies is available in Supplementary Information Table S3. An elaborate description and discussion of the building parts as well as the energy end uses covered in the investigated studies is provided in section 5.3.2 Material modelling and section 5.3.3 Energy modelling, respectively.

\subsection{Dynamic aspects and scenario variables}

The definition of static and dynamic aspects in the LCA of buildings stocks follows the definition of Mastrucci et al. in their related review [12], where 'static' means the assessment of the situation at a given time or the comparison of two distinct states in time. In contrast, 'dynamic' modelling considers the evolution of the building stock over time. The review of Göswein et al. [13] suggested a further differentiation of dynamic aspects considering spatial, (evolutionary) temporal, and spatial-cohort dynamics. In this study, we adopt a combined approach considering three types of dynamics. First, spatial dynamics, as the spatial differentiation in the baseline model, e.g., of building characteristics in different geographical or climatic areas. Second, temporal dynamics, as consideration of changes over time, e.g., changes to demand for space, user behaviour, and technological innovation in energy or material production. Third, spatial-temporal dynamics, as changes over both space and time, e.g., diversification of properties for some buildings (spatial dynamic) over time (temporal dynamic) due to retrofit activities or changes in use.

Table 1 presents an overview of the dynamic aspects identified in the final sample of studies. The table is structured to cluster cases based on related steps in environmental modelling, i.e., modelling of foreground inventory, background inventory, or impact assessment. We define the foreground inventory as the definition of types and quantities of buildings, elements and systems as well as construction materials and operational energy and water along the life cycle of the buildings. The background inventory relates to the conditions of material and energy related processes and the use of respective LCA data for modelling the life cycle of materials and energy flows (as specified in foreground inventory), e.g., production of $1 \mathrm{~kg}$ of material type X, or $1 \mathrm{kWh}$ of energy type $\mathrm{Y}$.

In the final sample for this review, half of the studies present a static assessment of the building stock. This means, for example, that for the energy modelling, the heating degree days (HDD) are considered constant and energy mixes are kept unchanged throughout the study timeframe. Some static models, however, include scenarios or variations to improve the model accuracy by considering, e.g., different renovation scenarios or varying energy mixes [17,32,24] In their scenario analyses, some studies focus on different renovation scenarios [20,21,26,31,33], while others vary energy mixes to study their influence on the environmental impacts during operation $[16,28,23]$. Five studies include dynamic climate or weather data $[20,21,26,27,36]$. It should be noted that the four studies of Krarti et al. [20,21,26,27] are, for the most part, based on a common methodology. In terms of temporal dynamics, two studies explicitly present the change in environmental impacts over time $[31,34]$, and four studies present the change in material flows $[28,34$, $18,23]$. Finally, individual studies focus on other dynamic aspects, e.g., the influence of changing recycling rates [29], of changing financial investment capacity per year [33]' and of population growth [28] and related trends in the use of floor area per capita [18].

\subsection{Inventory modelling and analysis}

The subsequent sections present our findings regarding inventory modelling and analysis for three main modules of environmental building stock models: (a) building stock aggregation, (b) material modelling, and (c) energy modelling. We also present an analysis of the various data sources used in the reviewed literature. An extended overview of the data sources as well as tools and software used in the reviewed studies for the modelling of these aspects are provided in Supplementary Information Table S4 and in the Supplementary Data file.

\subsubsection{Building stock characterization and aggregation}

5.3.1.1. Modelling. Fig. 5 shows six features of the different building stock aggregation approaches and their interrelationship: the object of assessment (existing building stock, new buildings, retrofits, new buildings and retrofits, or materials and urban mining), the scale of the stock (building, urban, regional, national, or transnational), the number of buildings in the actual stock, the number of archetype variations used for modelling (as well as segmentation criteria applied to differentiate archetype variants), the aggregation approach (archetype, building by building, or sample) and life cycle scope (embodied, operational, or both). First, as noted earlier, it is clear that almost half of the studies focus on the national level (10), just over a quarter on the urban scale (6) and the remainder on either the transnational (4), regional (1) or 
Table 1

Examples of dynamic aspects identified in the final sample of studies.

\begin{tabular}{|c|c|c|c|c|c|}
\hline \multicolumn{3}{|c|}{ Dynamic aspects in modelling steps } & \multicolumn{3}{|l|}{ Types of dynamics } \\
\hline Step & Aspects & Examples & Spatial & Temporal & Spatial-temporal \\
\hline \multirow[t]{3}{*}{$\begin{array}{r}\text { Foreground } \\
\text { inventory }\end{array}$} & $\begin{array}{l}\text { Demand for space, } \\
\text { occupant behaviour and } \\
\text { comfort }\end{array}$ & $\begin{array}{l}\text { Population projections; Typology of } \\
\text { family; Floor area per capita; Presence } \\
\text { time of occupants; Thermal comfort } \\
\text { levels }\end{array}$ & $\begin{array}{l}\text { Building stock classification in } \\
\text { different climatic zones or } \\
\text { geoclusters }[22,25,28,34]\end{array}$ & $\begin{array}{l}\text { Projections for population and floor area demand } \\
{[23,28,31]}\end{array}$ & $\begin{array}{l}\text { Demand projections and sensitivity of floor area per } \\
\text { capita [18]; Building stock size and number of } \\
\text { buildings to be renovated [34] ; User behaviour and } \\
\text { related energy demand reduction scenarios [35]; } \\
\text { Sensitivity of dwelling size development [23] ; } \\
\text { Influence of changes to cooling and heating set } \\
\text { point, as well as illuminance [28] }\end{array}$ \\
\hline & $\begin{array}{l}\text { Building typologies and } \\
\text { archetype definitions }\end{array}$ & $\begin{array}{l}\text { Number and definition of representative } \\
\text { buildings; Differentiation of archetypes; } \\
\text { Changes in culture of design and } \\
\text { construction }\end{array}$ & $\begin{array}{l}\text { Differentiation of building types } \\
\text { and construction period [18,19, } \\
\text { 28-31] ; Considering building } \\
\text { quality and refurbishment needs } \\
\text { [37] }\end{array}$ & $\begin{array}{l}\text { Future need for detached housing based on } \\
\text { population assumptions [16]; } \\
\text { Future changes to market share of different building } \\
\text { types (SFH, MFH) in new buildings [23]; Changes in } \\
\text { renewal rates, building materials and energy } \\
\text { standards, building technology upgrades [18] }\end{array}$ & $\begin{array}{l}\text { Scenarios for energy retrofit (e.g. energy system } \\
\text { switch to renewable energy, improved energy } \\
\text { performance of the building envelope) }[17,19,24,25 \text {, } \\
32,33,35-37]\end{array}$ \\
\hline & $\begin{array}{l}\text { Building elements and } \\
\text { materials, technical } \\
\text { systems and energy use }\end{array}$ & $\begin{array}{l}\text { Material choice; uptake of technological } \\
\text { innovation; degradation of technical } \\
\text { performance of materials or systems; } \\
\text { Integration of renewable energy systems }\end{array}$ & - & $\begin{array}{l}\text { Investigation of future recycling rate scenarios [29]; } \\
\text { Material flow and embodied impacts of different } \\
\text { future renovation scenarios [31,34]; Scenarios for } \\
\text { future changes to rate of timber typologies, } \\
\text { low-impact concrete in new buildings [23] }\end{array}$ & $\begin{array}{l}\text { Localized yearly material output from building stock } \\
\text { turnover based on number of new construction, } \\
\text { rebuilt or refurbished buildings }[18,30]\end{array}$ \\
\hline \multirow[t]{2}{*}{$\begin{array}{r}\text { Background } \\
\text { inventory }\end{array}$} & $\begin{array}{l}\text { Material production, } \\
\text { processing, end-of-life }\end{array}$ & $\begin{array}{l}\text { Increased recycling content of new } \\
\text { construction materials; } \\
\text { Changes in recycling technologies and } \\
\text { energy recovery practices }\end{array}$ & - & Changes to energy mix for material production [23] & - \\
\hline & Energy mix scenarios & $\begin{array}{l}\text { Changes to energy mix (electricity, } \\
\text { heat), e.g. due to national policies and } \\
\text { regulations or market mechanisms }\end{array}$ & - & $\begin{array}{l}\text { Energy consumption and future electricity mix } \\
\text { changes [16] } \\
\text { Electricity grid evolution }[28]\end{array}$ & - \\
\hline \multirow[t]{2}{*}{$\begin{array}{l}\text { Impact } \\
\text { assessment }\end{array}$} & $\begin{array}{l}\text { Carbon uptake and } \\
\text { emissions }\end{array}$ & $\begin{array}{l}\text { Carbon uptake during growth of bio- } \\
\text { based materials; } \\
\text { Biogenic carbon storage in construction } \\
\text { products; } \\
\text { Biogenic carbon emissions at the end of } \\
\text { life of products }\end{array}$ & $\begin{array}{l}\text { Influence of biogenic carbon } \\
\text { consideration for different building } \\
\text { types [16] }\end{array}$ & $\begin{array}{l}\text { Dynamic impact assessment based on time- } \\
\text { dependendant impact aggregation matrix and carbon } \\
\text { storage from bio-based materials [34]; analysis of } \\
\text { dynamic carbon footprint methodology [31] }\end{array}$ & - \\
\hline & $\begin{array}{l}\text { Characterization and } \\
\text { weighting }\end{array}$ & $\begin{array}{l}\text { Temporal changes to characterization } \\
\text { and/or weighting factors; } \\
\text { Regionalisation of impact factors based } \\
\text { on process location }\end{array}$ & - & - & - \\
\hline
\end{tabular}




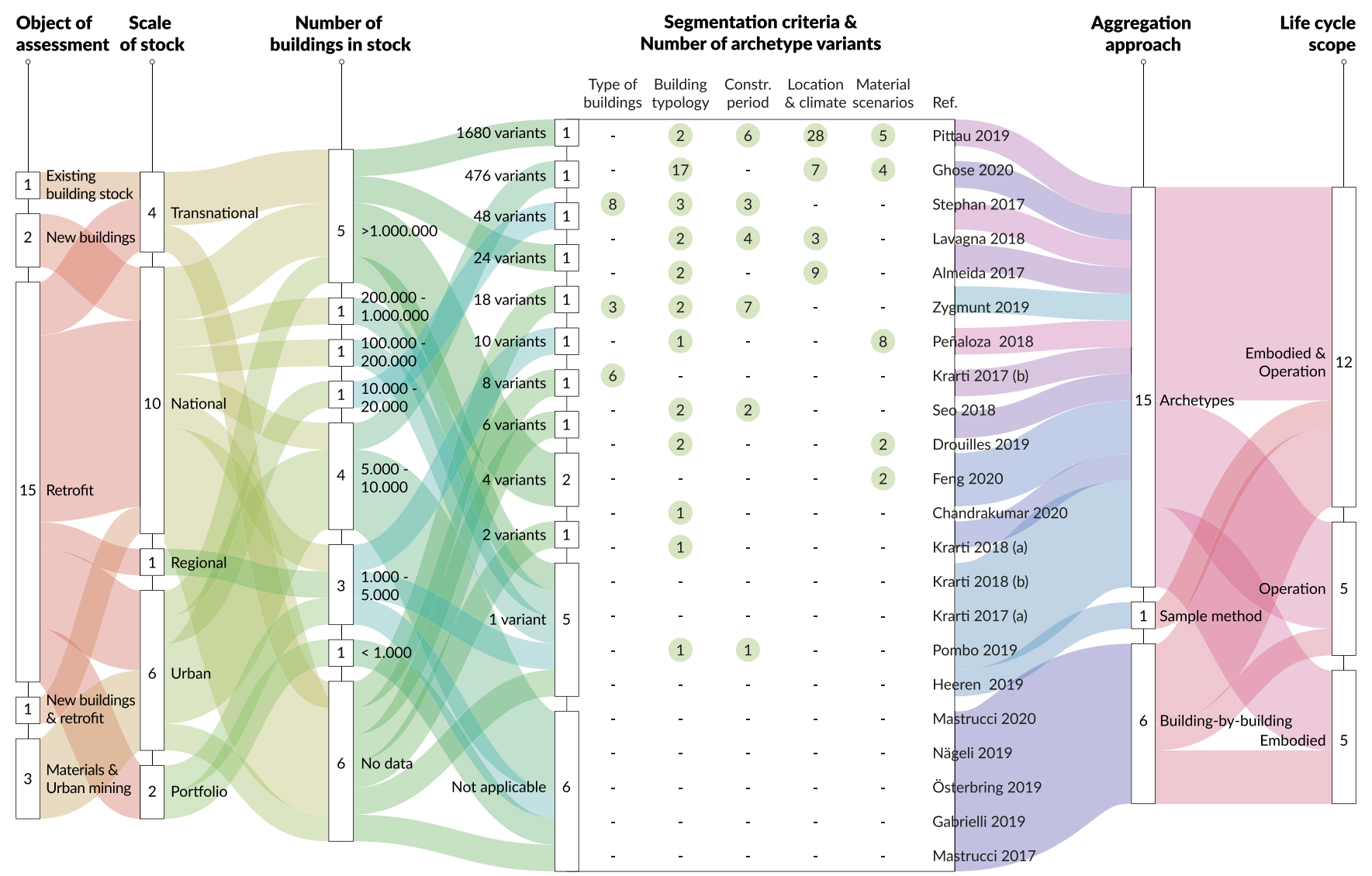

Fig. 5. Building typology, scale of the study, stock size, number of archetypes, aggregation approach and goal of the study.

building portfolio (2) scales. Second, although the number of buildings in the stock is not specified in six of the papers, the literature review shows that a larger scale of the stock tends to correspond to a larger number of buildings included in the stock. However, studies with a stock model size of over 1 million buildings, for example, may cover urban, national or transnational scales. Third, from the perspective of the connection between the number of buildings in the stock and the number of archetype variants, studies including a larger number of buildings (more than 10,000) always use the archetype approach. However, the segmentation criteria applied to differentiate buildings in the stock, as well as the overall number of archetype variants used for modelling, vary widely (from 1 to 1680) and do not necessarily correspond to the size of the stock under investigation. Fourth, the archetype approach is used in two-thirds of the studies, while only one study makes use of a sample method, and six studies implement a building-bybuilding model. Investigating the combination of characteristics in the individual studies, we observed that all studies taking a building-bybuilding approach are on a relatively small scale, covering a maximum of 10,000 buildings (or they do not report the number of buildings involved), and are conducted at the building portfolio, urban or national scale. The sample method is used in one study of multi-family houses at a national scale.

Fig. 5 further shows the segmentation criteria used to differentiate the archetypes and number of variants modelled for each criterion. We find that the building type (e.g., residential, office) or building typology (e.g., different types of residential buildings [SFH, MFH]) are the most common criteria. Studies further use the construction period, location or climate conditions as well as material scenarios (for both new construction and retrofit studies) to differentiate the archetypes. Overall, we find that several studies use a remarkably small number of archetype variants in their modelling of building stocks with several thousand buildings, which at times raises questions of the representativeness of the chosen archetype(s). At the same time, we find studies combining several criteria to generate several hundred archetype variants to model their building stock [28,34].

An overview of the building (stock) characteristics and their use for building stock characterization and clustering in the different studies is presented in Supplementary Information Table S5. We found that construction year and building type are the most used criteria for building stock characterization and clustering. These two characteristics commonly appear both individually and in combination. This combination is followed by the combination of the size and climate characteristics, which appears in every study clustering based on size and in three of the six studies [28,34,35,22,25,38] using climate zones as a clustering criterion. The combination of building typology and renovation state/need was identified three times.

5.3.1.2. Data sources. A variety of data sources were identified to obtain relevant information on building stock composition and characterization and to aggregate the building stock models. For studies not including a building-by-building case study analysis, we obtained building information by consulting various data sources to fill gaps in the data. Ten out of the 22 studies use statistical data on demographics and building information. These statistical data include national open source datasets $[36,18,30]$ and generalized datasets regarding building parameters such as type of use or geometry [31-34]. Five papers fill gaps using data from other studies on building stock levels to estimate the climate impact [16], determine quantities of building materials [23,29] or apply the methodology developed in a previous paper [35] (by the same author). Another five studies use geographical information systems (GIS) data to identify building geometry and fills gaps in building use data [31-33,18,29,30]. Seven studies make use of building (stock) databases such as, among others, TABULA [34,22] to establish building stock compositions, retrofit steps and timing $[31,18,29,30]$ or archetype 


\section{Level of Detail of Modelling and/or Results Presentation}

\begin{tabular}{|c|c|c|c|c|c|c|}
\hline & $\begin{array}{l}\text { Building cluster } \\
\quad(\text { Level }+1)\end{array}$ & $\begin{array}{l}\text { Building level } \\
\text { (Level 0) }\end{array}$ & $\begin{array}{l}\text { Building element } \\
\text { (Level -1) }\end{array}$ & $\begin{array}{l}\text { Sub-element } \\
\text { (Level -2) }\end{array}$ & $\begin{array}{c}\text { Construction material } \\
\text { (Level -3) }\end{array}$ & $\begin{array}{c}\text { Raw material } \\
\text { (Level -4) }\end{array}$ \\
\hline Modelling & 0 & 3 & 14 & 3 & 5 & 1 \\
\hline Results & 13 & 14 & 2 & 0 & 2 & 0 \\
\hline N/A & 9 & 5 & 6 & 19 & 15 & 21 \\
\hline
\end{tabular}

Fig. 6. Identified level of detail used for modelling and/or results presentation.

definitions. In addition, probabilistic approaches [31] and existing studies at the building level [17] are used. An overview of data sources used for the inventory modelling in different studies is presented in Supplementary Information Table S4 and in the Supplementary Data file.

\subsubsection{Material modelling}

5.3.2.1. Modelling. This section presents an investigation of the material inventory modelling and analyses, as identified in the reviewed literature. Overall, we identified that most studies follow the element method; i.e., they model material inventories in a hierarchical way based on building elements and their material composition. Strong variation was identified, however, in the context of the model resolution and level of detail in the hierarchical models. In Fig. 6, we thus analysed the resolution of both the modelling and the reporting of material- related impacts, based on the levels of modelling used in the Belgian building and building stock LCA tool in Ref. [39] and referring to the levels of investigation as outlined in the European EF guidelines and their application to the building level in the PEF4Buildings pilot project [40].

We found that 14 studies model the stock from the level of building elements, which are aggregated to represent buildings and the building stock. Few studies apply modelling levels below the element level. Subelement-level modelling is used in three studies and construction material-level modelling in five; only one study includes in its inventory the modelling of raw materials (i.e., the use of raw materials in construction products, e.g., according to the Eurostat raw material categories of biomass, metal ores, non-metallic minerals, and fossil energy materials).

The results are expressed mostly at the building and building stock levels. In general, we observed a lack of results presented at a higher

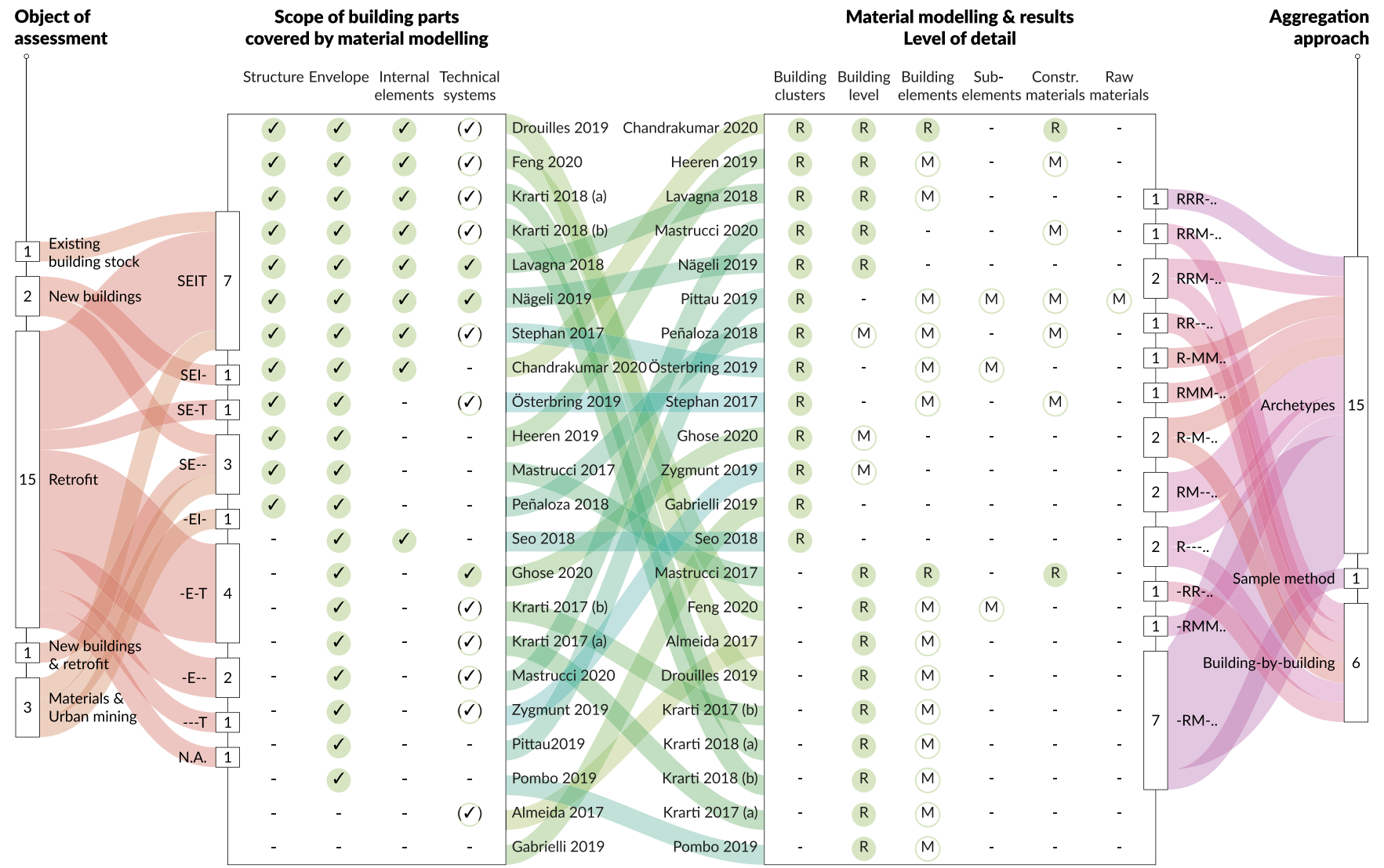

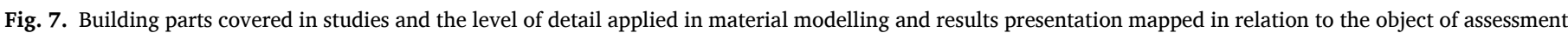

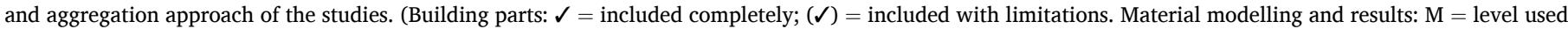
for modelling; $\mathrm{R}=$ level at which results are presented.). 
resolution than the element level and a lack of environmental hotspot analyses across different levels, which are crucial for the environmental optimization of buildings, construction products and related supply chains. The topic of hotspots in terms of environmental indicators is discussed further in section 5.4.

Fig. 7 provides further information on the scope of the reviewed studies in terms of building parts included in the assessment as well as on the level of detail for material modelling and results presentation. We found that the studies investigate different objects, with a variety of building parts covered in the assessments. While most of the studies likely make use of quantity information and background data at the material level, many of them do not explicitly show this in the documentation of their modelling approach or the life cycle inventories presented. Analysing the most complete studies from this perspective, we found seven studies with a comprehensive scope [17,32,36,20,22, 41], i.e., covering building parts related to structural systems, envelopes and façades as well as internal elements and technical systems (some with limitations). The objects of assessment range from the current state of the existing building stock or investigation of retrofit measures to material-focused and urban mining studies. We found that four of the seven studies $[17,36,20,41]$ are modelled at the element level and present the results at the building level. Of these, the sub-element level is utilized by one study [17]. For another three studies, we also identified modelling at the sub-element level [33] with the results presented at the building cluster level [32,22]. While some studies display a comprehensive focus on the building elements covered, others focus exclusively on one part of the building system. The latter is the case, for example, for retrofit studies focusing on the building envelope.

In terms of modelling material-related inventories and the presentation of related environmental impact results, we identified a wide variety of approaches. We found that in general, various levels of detail are used for modelling when an archetype-based aggregation approach is deployed. Multiple levels of modelling are utilized in four archetypebased studies [16,33,34,23]. While also differing in their use of modelling levels, studies applying a building-by-building approach tend to utilize more levels of material modelling and more often use these levels to present the results in terms of both material inventories and environmental impacts. Utilization of several levels of modelling is presented in four out of the five building-by-building studies [31,18,29, 30].

From an overall perspective, while some studies were identified that either displayed a comprehensive scope in terms of building elements $[17,32,36,20,22,41]$ or offered a comparably detailed modelling of material-related inventories $[16,34,18,23,29,30]$, none of the studies could be identified as providing both at the same time. However, considering the variety of combinations found in terms of objects of assessment, building part scopes, levels of material modelling and aggregation approaches, lessons can be learned from these existing approaches to advance building stock modelling practices to achieve comprehensive and detailed modelling of material-related environmental impacts.

5.3.2.2. Data sources. We found a variety of material-related data sources. Several studies utilize statistical data from building material and element databases such as the КBOB database for Switzerland [36] or, in the Australian context, data from the national bureau of statistics [24] or the dedicated CLUE building material database [30]. Several studies base their analysis of material-related impacts on previous studies at the building stock level (as in Ref. [28], which is largely based on previous research by the same authors [42]) or, more commonly, at the building level. Prior studies at the building level are frequently utilized, based on LCA data from BRANZ for New Zealand in the case of

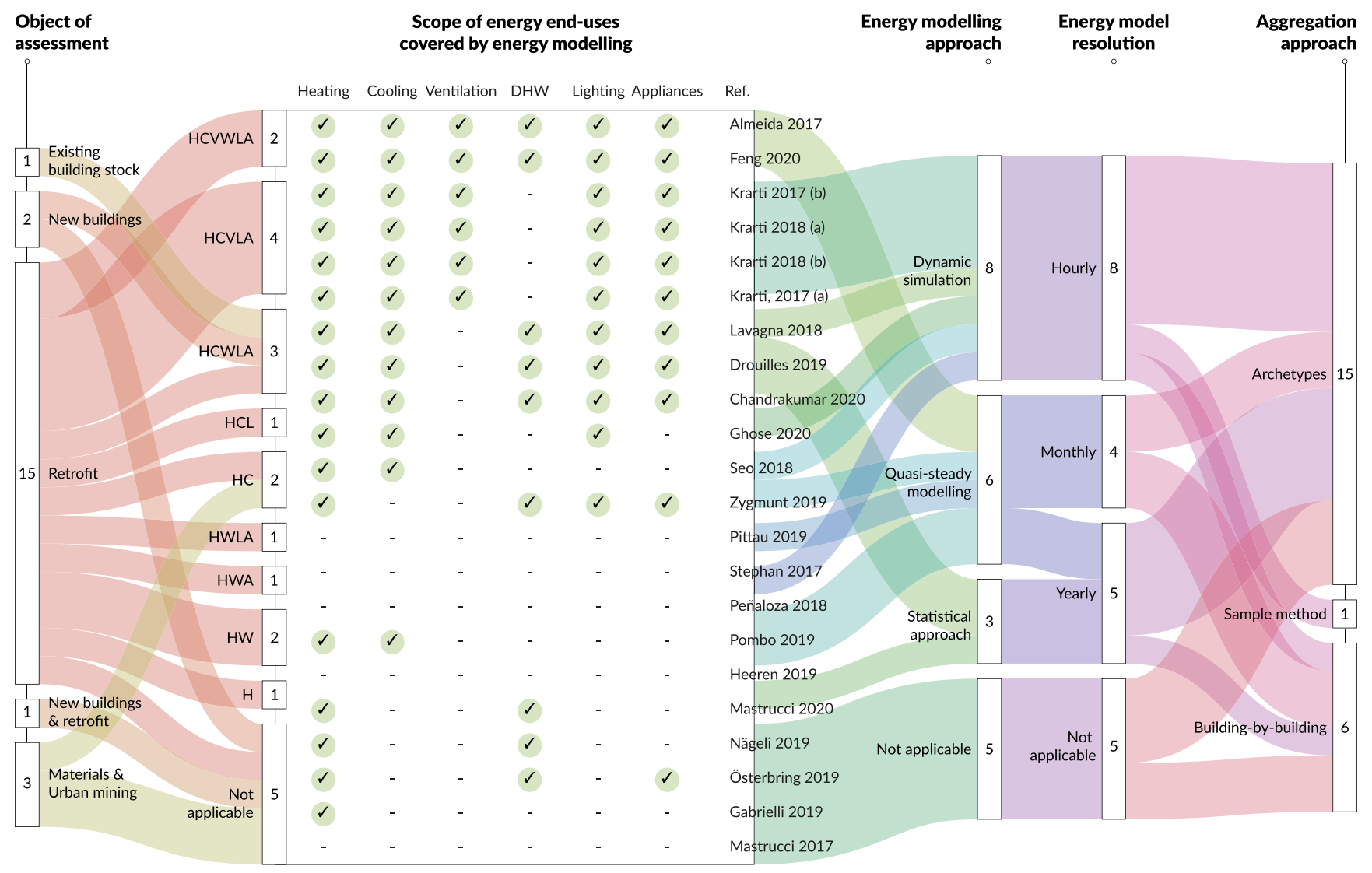

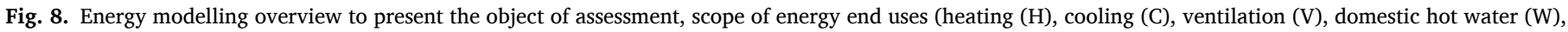
lighting (L), or appliances (A)) plus the energy modelling approach, model resolution and aggregation approach applied. 
[16], material data on representative buildings for Luxembourg in Ref. [29], or data and reports from related research projects such as IEA EBC Annex 56 ("Cost-Effective Energy and Carbon Emissions Optimization in Building Renovation") in Ref. [25]. Databases on building or building stock data are used in several studies, especially in the European context. Such studies use data from projects such as TABULA, EPISCOPE, ENTRANZE, ODYSSEE or the European Building Stock Observatory [34,22] as well as building data from national or local building libraries [31,29]. Other data used include material-related data from building energy performance certificates [33] or material-relevant information from building energy cost data for maintenance and building services [32]. Regulations and standards are utilized to obtain information to model end-of-life scenarios and impact coefficients [29] or building envelopes according to existing thermal performance requirements [31]. We further identified the use of probabilistic approaches for projecting element service life and the timing of replacements [18] as well as for modelling past renovations and future renovation needs with statistics-based random distributions [31]. A complete overview of data sources used for inventory modelling in different studies is presented in Supplementary Information Table S4 and the Supplementary Data file.

\subsubsection{Energy modelling}

5.3.3.1. Modelling. This section presents a detailed investigation of the energy modelling and analyses identified in the reviewed literature.

Fig. 8 shows the different approaches used to model the operational energy demand and related environmental impacts. Based on the objects of assessment, we documented the scope of energy end uses considered in the modelling. The energy end uses documented are heating $(\mathrm{H})$, cooling (C), ventilation (V), domestic hot water (W), lighting (L), and other appliances (A). We observed two studies covering the full scope in terms of energy end uses (i.e., HCVWLA). These studies base their modelling on a monthly or yearly resolution of energy use. No studies combining a comprehensive end-use scope with the highest (hourly) resolution in energy modelling could be identified. We found eight studies that employ dynamic energy simulation and six that employ steady or quasi-steady modelling. When a steady simulation is applied, the resolution time step is yearly or monthly, whereas dynamic simulation is always conducted with an hourly time step resolution. We identified only three papers applying a statistical approach, and in these cases, a yearly resolution is utilized.

Among the papers with bottom-up statistical models, [37] is the only one that develops a multiple linear regression equation to estimate building energy demand. One study uses a top-down approach to calculate the energy consumption of each archetype in the baseline scenario [22]. As a further development of this study, Allacker et al. [43] perform dynamic energy simulation on the archetypes defined in Lavagna et al. [22] to assess the life cycle environmental burdens and benefits of some eco-innovation measures. Chandrakumar et al. [16] use a statistical approach to calculate the variations in energy sources in the future. Seo, Foliente and Ren [24] utilize statistical data to obtain the energy consumption of the construction sector and to quantify the embodied environmental impacts of retrofitting. Furthermore, they model heating and cooling energy requirements using an energy simulation tool to calculate the benefits of improved energy performance in residential buildings.

5.3.3.2. Data sources. The analysis of the data sources for the energy modelling showed that statistical data and regulations and standards are the most used sources.

Statistical data are utilized for different objectives, e.g., to acquire the national energy consumption of the construction sector [24], to obtain the share of energy carriers in households [19] or to cover heating and domestic hot water demand by type of building and construction period [36]. Statistical data are combined with individual national energy mixes to define the energy consumption of each archetype in Lavagna et al. [22]. National and international regulations and standards are mostly used as a reference to calculate energy demand through simulations [32,35,37,19,25]. Standards and regulations are considered to develop energy performance scenarios in two studies [36, 24]. Two studies define the geometric characteristics of buildings using GIS data provided by city planning offices and apply these data for energy calculations $[32,33]$. The same two studies also utilize building energy performance certificates (EPCs) as a data source for information on heating and ventilation systems, the average number of apartments, building height and measured energy use [32,33].

\subsubsection{LCA scenarios}

LCA studies typically use scenario modelling to assess the influence of certain parameters on the overall results. The literature review checked for which parameters such scenario analysis was performed, identifying the following parameters: estimated service life (ESL) and reference study period (RSP), recycled content versus primary material use, refurbishment scenarios, and end-of-life scenarios.

In ten studies, special attention is paid to specifying the ESL. In three studies $[17,28,33]$, the ESL is defined by building element, while one study defines an overall RSP of 100 years for the building itself [22]. Four studies state the RSP, varying from 25 years [24] to 60 years [34, 35] after renovation, at the building level only. Pittau et al. [34] and Pombo et al. [35] further conduct a sensitivity analysis to examine a shorter ESL of building elements and buildings to evaluate the influence of ESL on the overall results. Only one study includes a sensitivity analysis to test the impacts and implications of substituting primary material with recycled content [18].

Various different renovation measures are investigated in seven of the studies in our sample $[17,28,31,35,18,19,25]$. One study investigates the financial implications of renovation activities at the urban scale for different renovation measures by studying the maximum renovation rate for a certain measure as a function of households' investment capacity [33].

In the majority of the papers, end-of-life scenarios are not included. Pittau et al. [34] include three disposal scenarios. In the paper of Mastrucci et al. [29], the business-as-usual scenario is compared to a second scenario where an increased down-cycling rate for inner waste is assumed. The study of Heeren et al. [18] includes a sensitivity analysis for recycling and reuse scenarios for concrete, wood and thermal insulation.

In conclusion, only a small number of studies include different LCA scenarios in their modelling and analysis of the building stock in terms of material- and energy-related impacts. Furthermore, the LCA scenarios are critically investigated through sensitivity analyses in only a few of the studies.

\subsection{Life cycle impact assessment}

This section reviews the life cycle impact assessment (LCIA) methods and related environmental indicators adopted by the selected studies. Our analysis refers to the LCIA methods and environmental indicators suggested in the European Committee for Standardization (CEN) standards (EN 15804, EN 15978). The methods and environmental indicators analysed in the reviewed studies are available in Supplementary Information Table S6.

First, we found that LCIA methods are rarely mentioned in the papers, even though various environmental indicators are assessed. All studies in our final sample assess environmental indicators of global warming potential (GWP). Out of the sample, 16 studies focus exclusively on this indicator. After GWP, the most common environmental indicators are acidification potential (AP), ozone depletion potential (ODP), eutrophication potential (EP) and photochemical ozone creation potential (POCP). The categories of water resource depletion and land 
use are considered by only two studies. The review of the EU policy documents, however, revealed that the importance of land use and land use change is increasing, especially under the Biodiversity Strategy. A building stock impact assessment should hence include land use indicators to support EU policy goals. Finally, we noted that in current studies, normalization and weighting are rarely implemented. Normalization is applied in only two studies [33,29], but no details on the method for normalization are provided. One study [22] uses the International Reference Life Cycle Data System (ILCD) method to normalize and weight the results.

\subsection{Strengths and limitations of studies}

As a final step towards identifying the potential of existing building stock modelling approaches to support policy as well as the required directions that such approaches should take to provide this support, we reviewed the strengths and limitations of the studies in our sample. An overview of these strengths and limitations, either as stated by the authors of the respective studies or as identified through our review, is presented in Supplementary Information Table S7. A summary of the findings is provided in this section.

Scenarios involving energy efficiency and refurbishments frequently report the potential for improvement in the considered studies. Six studies $[16,28,31,18,19,23]$ go even further by examining exogenous factors driving stock development, such as projected population growth and future evolution of the energy mix or the renovation rate. Seven studies [17,20,21,24,25,27,33,37] furthermore include cost analyses measuring the energy or impact improvements of projects against the payback time, related job creation or investment capacity, which are mentioned as topics for future work in two studies [28,32].

Not only the number of investigated impacts but also the level of detail in the assessments vary. One way of achieving a higher level of detail is by utilizing digital building stock information tools like GIS or building information modelling (BIM), which are implemented in four studies $[17,31,18,29]$ and stated as a requirement for future research in three more papers $[28,29,30]$. A higher level of detail is also seen in six studies [28,33,35,19,22,29] considering multiple environmental indicators. This is in contrast to the other studies, which include only $\mathrm{CO}_{2}$ or GHG emissions, although the reliance on these indicators is criticized internally in some cases [35,37,22]. Only two papers [36,22] achieve a full life cycle analysis by considering all life cycle stages. Three papers go beyond an environmental impact assessment by including policy impacts [33], mobility [36] or a social LCA [35]. The need for a higher level of detail regarding the spatiotemporal aspects applied in LCA is expressed in five papers [31,33,18,23,29].

Finally, to validate the quality of the results, almost half of the studies [16,28,31,34,37,18,22,23] include an uncertainty analysis where the influence of different model parameters is considered to evaluate the susceptibility to variation in outcomes. Only one study presents an uncertainty analysis [37] including the use of a probability distribution, although three other studies mention the need to conduct uncertainty analyses [36,23,29].

\subsection{Typology of methodological approaches}

This section provides an overview of the various methodological approaches and their characteristics. The description of the modelling approaches and methodological modules is a synthesis of the methodological frameworks presented in the reviewed studies. The modules are based on previous studies, e.g., IEA EBC Annex 31 [11] and the review by Mastrucci et al. [12], who defined the building aggregation model, energy model, and LCA model as relevant components of stock modelling. We expand the definition to six basic modules common to most of the studies, as presented in Fig. 9: i) building stock characterization; ii) material modelling; iii) energy modelling; iv) life cycle impact assessment; v) building stock aggregation; and vi) visualization and reporting. These represent the basic blocks of models for the environmental assessment of building stocks, as identified in our review.

Building stock characterization relates to the characterization and clustering of the building stock and the definition of representative buildings or archetypes or, where applicable, data processing for a building-by-building aggregation approach. Materials modelling relates to the modelling of building components and materials based on thermal, physical and other characteristics and with related calculation of replacements according to the ESL of building elements. Depending on the modelling approach, quantification of construction materials may be conducted for building elements (e.g., for application in both buildingby-building and archetype-based models) or for full buildings only (e. g., for use in archetype-based aggregation). Energy modelling refers to the determination of operational energy demand. The data and tools applied in this module strongly depend on the type of study and the energy modelling method applied (e.g., dynamic or quasi-steady approaches), which are discussed in section 5.3.3 Energy modelling. LCIA relates to the quantification of environmental impacts through the application of impact coefficients. The studies in our sample vary strongly in terms of the scope of the life cycle stages and environmental indicators covered. Hence, the data and tools used for LCIA also depend on the modelling approach and range from a simple application of

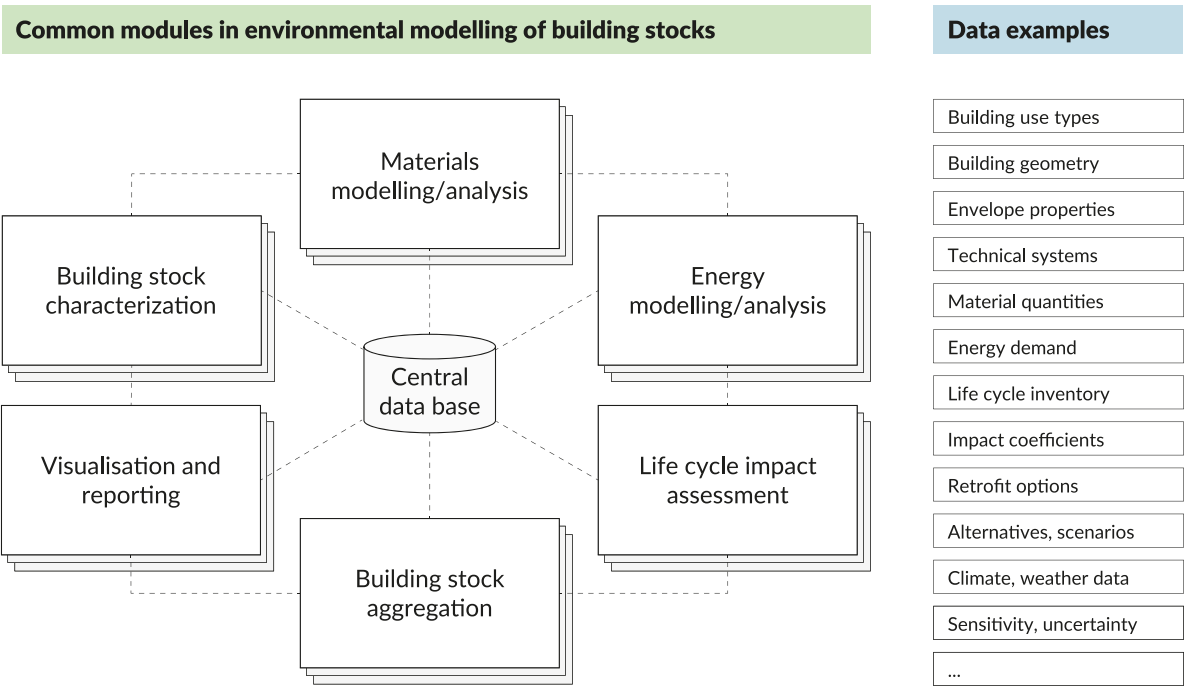

Fig. 9. Common modules in the environmental modelling of building stocks and examples of relevant data. 

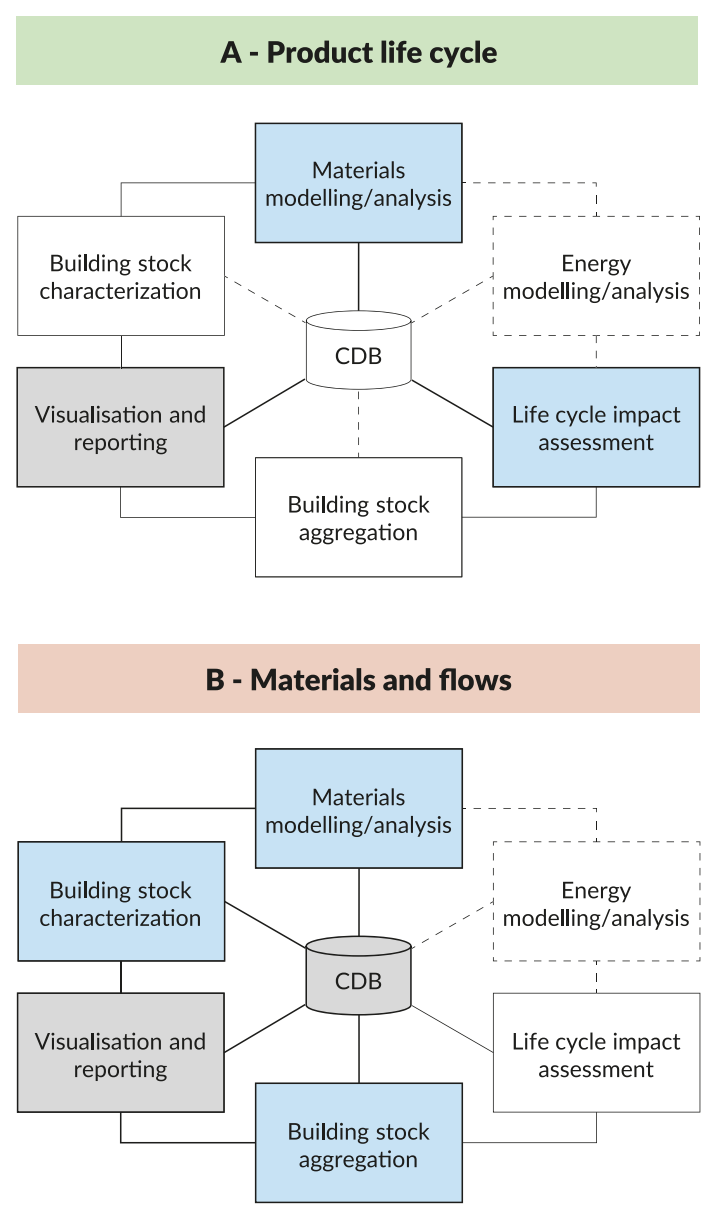

Core Common
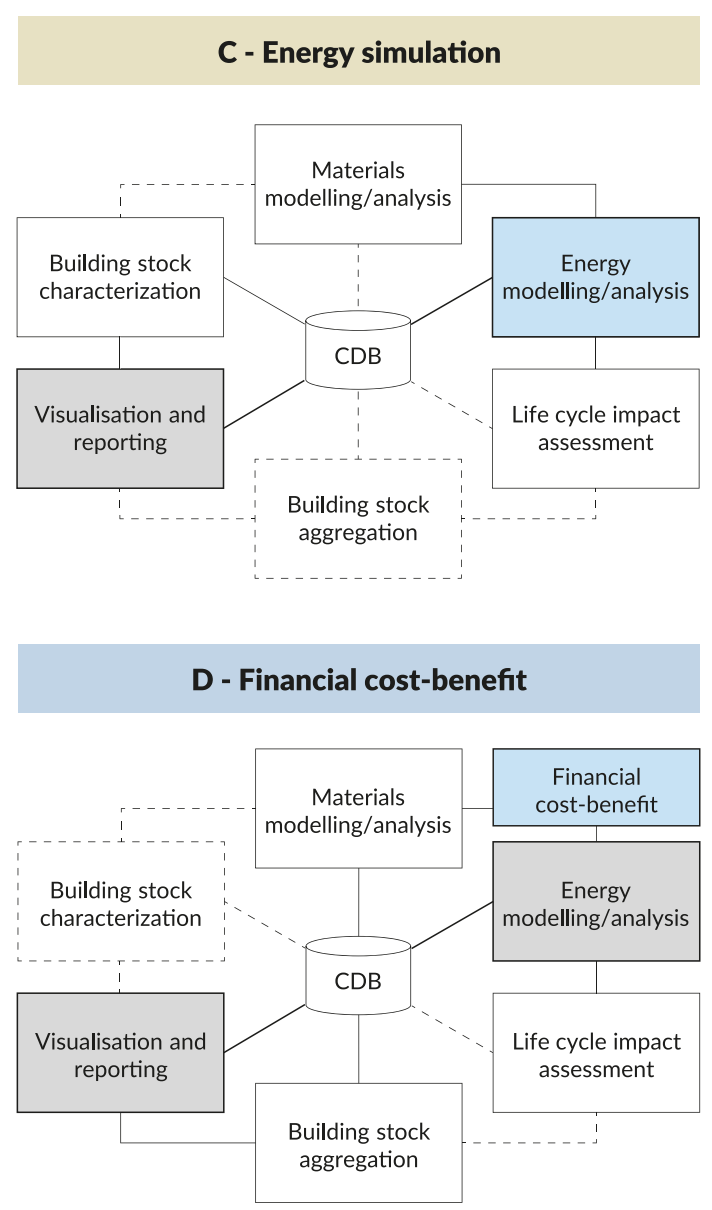

Limitations

Highlights

Fig. 10. Overview of the different modelling approaches and their core modules, highlights and limitations.

impact coefficients (i.e., multiplication of material quantities with the respective coefficients, e.g., kilos of $\mathrm{CO}_{2}$ eq per kilo of material) to the use of comprehensive LCIA methods with an extended set of environmental indicators and dedicated LCA software. Building stock aggregation is the process of aggregating the information obtained through materials and energy modelling and scaling up to the level of a building stock. In most studies, especially those using an archetype-based aggregation approach, this step is carried out after the LCIA. However, especially for studies using a building-by-building aggregation approach, impact assessment is often conducted after materials and energy information have been aggregated and scaled up to the level of the building stock. The important factor here is the ability of the models to maintain the level of detail in life cycle inventories and impact assessment as they scale up to the level of the building stock. Eventually, visualization and reporting are conducted to interpret and communicate the results of the study and report the findings accordingly. Depending on the type of study, different tools and visualization options - ranging from bar charts or heat maps to show the contribution of different life cycle stages or building parts to spatialized visualizations of assessment results on geographical maps - may be utilized.

For some studies, we could observe the use of a central database or a common data environment to manage the large variety and quantity of data to be processed in complex building stock models. Furthermore, the data processed in the respective modules may follow one definition or contain multiple alternative solutions, as is the case in investigations of different scenarios, e.g., for different retrofit strategies in material modelling or climate change scenarios in energy modelling.
Considering these six modules, we distinguished the stock modelling approaches into four types: type A, product life cycle approach; type B, materials and flows focus; type $\mathrm{C}$, building energy simulation; and type $\mathrm{D}$, cost-benefit analysis. Based on their specific perspectives and focuses, modelling approaches were found to fit one type or a combination of several types. Fig. 10 presents the four modelling approaches, indicating the common modules, the modules that are core to the approach, and the limitations or strengths (highlights) of the approach.

Table 2 provides a detailed description of the characteristics identified for the different modelling approaches. A detailed description of an exemplary modelling approach is available in Supplementary Information Figure S2.

To relate the identified modelling approaches to the goal and scope of the studies, their life cycle inventory modelling and analysis, we present a compilation of the data extracted on the spatiotemporal scope of studies, their aggregation method and the methodological approach in Table 3.

\section{Discussion in context of EU policy}

\subsection{Relevance of this study in the EU policy cycle}

The findings of this study are expected to be useful in supporting environmental, energy and product policies related to buildings, particularly in the EU context. Learnings from the models reviewed in this study will support policies mainly in two steps of the policy cycle (as outlined in Fig. 1): 1. The policy anticipation and problem definition, 
Table 2

Description of modelling approach scope and system boundaries as well as tools and software for modelling.

\begin{tabular}{|c|c|c|c|c|}
\hline \multirow[b]{2}{*}{ Description } & \multicolumn{4}{|c|}{ Modelling approaches } \\
\hline & A: Product life cycle & B: Materials and flows & C: Energy simulation & D: Cost-benefit \\
\hline \multicolumn{5}{|l|}{ Summary } \\
\hline Context & $\begin{array}{l}\text { Background in environmental LCA of } \\
\text { products. Detailed models of the } \\
\text { building across its life cycle, scaled to } \\
\text { stock using archetypes. Often } \\
\text { combined with energy models (type C) }\end{array}$ & $\begin{array}{l}\text { Background in industrial ecology } \\
\text { and urban metabolism research. } \\
\text { Customized approaches for } \\
\text { extending material flow analysis } \\
\text { (MFA) with LCA, use of GIS }\end{array}$ & $\begin{array}{l}\text { Background in energy modelling, } \\
\text { dynamic simulation of buildings. } \\
\text { Mostly applied for analysing stock } \\
\text { refurbishment. Often combined with } \\
\text { cost-benefit models (type D) }\end{array}$ & $\begin{array}{l}\text { Models focusing on identifying the } \\
\text { financial cost-benefit optimum for } \\
\text { retrofit measures applied at the } \\
\text { stock level. Often combined with } \\
\text { energy models (type C) }\end{array}$ \\
\hline \multirow[t]{2}{*}{ Strengths } & Full life cycle scope (cradle to grave) & $\begin{array}{l}\text { Flexibility regarding } \\
\text { spatiotemporal scope, level of } \\
\text { modelling detail }\end{array}$ & $\begin{array}{l}\text { Support for dynamic energy } \\
\text { simulation of future climate } \\
\text { scenarios }\end{array}$ & $\begin{array}{l}\text { Support for identification of cost- } \\
\text { effective solutions (some studies } \\
\text { include other market-related }\end{array}$ \\
\hline & $\begin{array}{l}\text { Hotspot analysis at building level } \\
\text { (parts, materials, life cycle stages) }\end{array}$ & $\begin{array}{l}\text { Scalable across stock sizes (if data } \\
\text { available) }\end{array}$ & & aspects) \\
\hline Limitations & $\begin{array}{l}\text { Aggregation based mostly on a limited } \\
\text { number of archetypes, with exceptions }\end{array}$ & $\begin{array}{l}\text { Energy modelling often simplified } \\
\text { or not included at all }\end{array}$ & $\begin{array}{l}\text { Limited to operation or in-use phase, } \\
\text { focused mostly on refurbishment }\end{array}$ & $\begin{array}{l}\text { Aggregation based on an often- } \\
\text { limited number of archetypes }\end{array}$ \\
\hline \multicolumn{5}{|c|}{ Scope, system boundaries, indicators } \\
\hline \multirow[t]{2}{*}{$\begin{array}{l}\text { Building stock } \\
\text { scale }\end{array}$} & $\begin{array}{l}\text { Stocks from regional to transnational } \\
\text { scale, no urban scale studies }\end{array}$ & $\begin{array}{l}\text { Stocks from urban to transnational } \\
\text { scale }\end{array}$ & Stocks mostly on national scale & $\begin{array}{l}\text { Stocks from portfolio to national } \\
\text { scale }\end{array}$ \\
\hline & Timeframe $30-50$ years & Timeframe $25-200$ years & Timeframe $4-35$ years & Timeframe $20-35$ years \\
\hline Life cycle stages & Cradle to grave (full life cycle) & $\begin{array}{l}\text { Various: Cradle to grave (with } \\
\text { limitations), production, end of use }\end{array}$ & \multicolumn{2}{|c|}{ Operation, in use (including materials replacement, refurbishment) } \\
\hline $\begin{array}{l}\text { Building parts, } \\
\text { materials }\end{array}$ & \multicolumn{2}{|c|}{$\begin{array}{l}\text { Various: Potential to cover all building parts (e.g., structure, envelope, } \\
\text { finishes, technical systems) }\end{array}$} & \multicolumn{2}{|c|}{$\begin{array}{l}\text { Focus on envelope (insulation, windows) and technical systems (heating, } \\
\text { cooling, domestic hot water [DHW], photovoltaic [PV]) }\end{array}$} \\
\hline Energy end uses & $\begin{array}{l}\text { Comprehensive scope (heating, } \\
\text { cooling, DHW, lighting, appliances) }\end{array}$ & $\begin{array}{l}\text { Various: Often no operational } \\
\text { energy use considered, as focus on } \\
\text { materials }\end{array}$ & $\begin{array}{l}\text { Comprehensive scope (see type A). } \\
\text { Only type considering ventilation }\end{array}$ & $\begin{array}{l}\text { Comprehensive scope (see type A, } \\
\text { some combinations with type C) }\end{array}$ \\
\hline $\begin{array}{l}\text { Impact } \\
\text { assessment, } \\
\text { indicators }\end{array}$ & \multicolumn{3}{|c|}{$\begin{array}{l}\text { Various: Most studies focus on GHG-related indicators, independent of model type; some present comprehensive scope } \\
\text { (e.g., CEN indicator set). Extending list of environmental indicators seems feasible for most approaches }\end{array}$} & $\begin{array}{l}\text { Only GHG-related indicators (e.g., } \\
\text { GWP) }\end{array}$ \\
\hline \multicolumn{5}{|c|}{ Modelling, data and tools } \\
\hline $\begin{array}{l}\text { General } \\
\text { framework, data } \\
\text { and tools }\end{array}$ & - & $\begin{array}{l}\text { Use of tools for scripting (e.g., R, } \\
\text { Python) and database management } \\
\text { (e.g., PostgreSQL) }\end{array}$ & - & $\begin{array}{l}\text { Often combined with dynamic } \\
\text { energy models (type C) }\end{array}$ \\
\hline $\begin{array}{l}\text { Building stock } \\
\text { characterization }\end{array}$ & $\begin{array}{l}\text { Statistical data (national statistics, } \\
\text { energy performance, TABULA, } \\
\text { EPISCOPE) }\end{array}$ & $\begin{array}{l}\text { Statistical data (geoclusters), GIS } \\
\text { tools (e.g., PostGIS, QGIS, GRASS } \\
\text { GIS) for building by building }\end{array}$ & $\begin{array}{l}\text { Statistical data (climate zone, energy } \\
\text { performance) }\end{array}$ & $\begin{array}{l}\text { Statistical data, characteristics of } \\
\text { buildings in portfolio }\end{array}$ \\
\hline $\begin{array}{c}\text { Building stock } \\
\text { aggregation }\end{array}$ & Archetype only & $\begin{array}{l}\text { Both archetype and building by } \\
\text { building }\end{array}$ & Archetype mostly, sample method & $\begin{array}{l}\text { Archetype mostly, building by } \\
\text { building }\end{array}$ \\
\hline $\begin{array}{l}\text { Materials } \\
\text { modelling }\end{array}$ & $\begin{array}{l}\text { Based on plans, documentation. Some } \\
\text { use of BIM models to obtain building } \\
\text { material information, quantities (e.g., } \\
\text { Autodesk Revit) }\end{array}$ & $\begin{array}{l}\text { Element composition based on } \\
\text { statistics (material use) and } \\
\text { functional requirements } \\
\text { (regulations) }\end{array}$ & $\begin{array}{l}\text { Often combined with life cycle } \\
\text { models (type A) }\end{array}$ & $\begin{array}{l}\text { Focus on operation, only one study } \\
\text { considers embodied impacts of } \\
\text { retrofitting }\end{array}$ \\
\hline Energy modelling & $\begin{array}{l}\text { Based on statistics or quasi-steady } \\
\text { approach. Often combined with energy } \\
\text { models (type C) }\end{array}$ & $\begin{array}{l}\text { Quasi-steady approach mostly. } \\
\text { Some use of dedicated tools for } \\
\text { building energy use modelling (e. } \\
\text { g., ECCABS model) }\end{array}$ & $\begin{array}{l}\text { Only type using dynamic energy } \\
\text { simulation (e.g., DesignBuilder, } \\
\text { EnergyPlus), as well as quasi-steady } \\
\text { approach }\end{array}$ & $\begin{array}{l}\text { Quasi-steady and/or dynamic } \\
\text { energy modelling tools (e.g., } \\
\text { AccuRate, EnergyPlus) }\end{array}$ \\
\hline $\begin{array}{l}\text { Life cycle impact } \\
\text { assessment }\end{array}$ & $\begin{array}{l}\text { Use of dedicated LCA tools (e.g., } \\
\text { SimaPro) and databases (e.g., } \\
\text { ecoinvent) }\end{array}$ & $\begin{array}{l}\text { Script-based LCA tools (e.g., } \\
\text { Brightway2, SimaPro) }\end{array}$ & - & Common use of impact coefficients \\
\hline
\end{tabular}

namely the identification of issues that need to be regulated via a policy (e.g., issues that are generating environmental impacts or concerns); 2. The modelling and comparison of environmental implications of different policy options in the policy formulation and impact assessment steps of the policy cycle. This study hence provides support on those steps for policymaking where policies are involving issues related to the building stock, building construction and operation, particularly.

\subsection{Learnings for supporting EU policy making}

\subsubsection{Methodological approaches}

In this study, the existing methodological approaches are described and categorized into four types of methodological frameworks with different foci in their modelling, as discussed in section 5.6. Combinations of approaches were also identified in the current literature, with multiple models (or the results from various research papers) often integrated in one study. Learning from and combining existing approaches found in the latest literature can inform comprehensive approaches to environmental modelling of building stocks to support EU policy making.
Nevertheless, existing modelling approaches need to be better integrated and combined to enable comprehensive and detailed modelling of building stock evolutions and related environmental impacts to support EU policy in the coming decades.

\subsubsection{Goal and scope}

We found that most studies investigate prospective timeframes up to 2050 and hence support an assessment of environmental targets and mitigation pathways up until mid-century. Only a few studies project further into the future. Investigating building stock development until the end of the century, however, could well be relevant, especially considering mitigation scenarios that include negative emissions in the second half of the century, with biogenic carbon storage in buildings potentially playing an important role.

\subsubsection{Dynamics aspects and scenario variables}

While also relying on many static parameters, existing studies consider various dynamics of building stock development. Dynamic aspects cover both the inventory and the impact assessment side and our analysis shows examples of different dynamic aspects and where they 
Table 3

Modelling approaches and spatiotemporal scope of studies.

\begin{tabular}{|c|c|c|c|c|c|c|c|c|c|c|c|}
\hline \multirow[t]{2}{*}{ Reference } & \multirow[t]{2}{*}{ World Region } & \multirow[t]{2}{*}{ Scale of the study } & \multirow{2}{*}{$\begin{array}{c}\text { Object of } \\
\text { assessment }\end{array}$} & \multirow[t]{2}{*}{ Type of buildings } & \multirow[t]{2}{*}{ Life cycle scope } & \multirow{2}{*}{$\begin{array}{c}\text { Modelling } \\
\text { approach (Abbr.) }\end{array}$} & \multirow{2}{*}{$\begin{array}{l}\text { Modelling } \\
\text { approach }\end{array}$} & \multicolumn{4}{|c|}{ Modelling approaches } \\
\hline & & & & & & & & A: Product life & B: Materials and & C: Energy & D: \\
\hline Almeida and & Europe & Transnational & Retrofit & Residential & Embodied \& & $\mathrm{C}$ & Energy simulation & - & - & $\checkmark$ & - \\
\hline Chandrakumar et & Australia and & National & New buildings & Residential & Embodied \& & $A+C$ & Product life cycle & $\checkmark$ & - & $\checkmark$ & - \\
\hline Drouilles et al. & Europe & National & Retrofit & Residential & Embodied \& & $A+C$ & Product life cycle & $\checkmark$ & - & $\checkmark$ & - \\
\hline Feng et al. 2020 & North America & Urban & Retrofit & Residential & Embodied \& & $A$ & Product life cycle & $\checkmark$ & - & - & - \\
\hline Gabrielli and & Europe & Portfolio & Retrofit & Non-residential & Operation & D & Cost-benefit focus & - & - & - & $\checkmark$ \\
\hline Ghose, McLaren, & Australia and & National & Retrofit & Non-residential & Embodied \& & $A+C$ & Product life cycle & $\checkmark$ & - & $\checkmark$ & - \\
\hline Heeren and & Europe & National & New buildings \& & Residential & Embodied & B & Materials and & - & $\checkmark$ & - & - \\
\hline Krarti and Dubey & Greater Middle & National & Retrofit & Full building stock & Operation & $C+D$ & Energy simulation & - & - & $\checkmark$ & $\checkmark$ \\
\hline Krarti and Dubey & Greater Middle & National & Retrofit & Residential & Operation & $C+D$ & Energy simulation & - & - & $\checkmark$ & $\checkmark$ \\
\hline Krarti and Dubey & Greater Middle & National & Retrofit & Residential & Operation & $C+D$ & Energy simulation & - & - & $\checkmark$ & $\checkmark$ \\
\hline Krarti, Dubey, & Greater Middle & National & Retrofit & Residential & Operation & $\mathrm{C}+\mathrm{D}$ & Energy simulation & - & - & $\checkmark$ & $\checkmark$ \\
\hline Lavagna et al. & Europe & Transnational & Existing building & Residential & Embodied \& & A & Product life cycle & $\checkmark$ & - & - & - \\
\hline Mastrucci et al. & Europe & Urban & Materials, Urban & Residential & Embodied & B & Materials and & - & $\checkmark$ & - & - \\
\hline Mastrucci et al. & Europe & Urban & Retrofit & Residential & Embodied \& & B & Materials and & - & $\checkmark$ & - & - \\
\hline Nägeli et al. 2019 & Europe & Portfolio & Retrofit & Residential & Embodied \& & $D$ & Cost-benefit focus & - & - & - & $\checkmark$ \\
\hline Österbring et al. & Europe & Urban & Retrofit & Residential & Embodied \& & $B+C$ & Materials and & - & $\checkmark$ & $\checkmark$ & - \\
\hline Peñaloza et al. & Europe & National & New buildings & Residential & Embodied & B & Materials and & - & $\checkmark$ & - & - \\
\hline Pittau et al. 2019 & Europe & Transnational & Retrofit & Residential & Embodied & B & Materials and & - & $\checkmark$ & - & - \\
\hline Pombo, Rivela, & Europe & National & Retrofit & Residential & Embodied \& & $A+C$ & Product life cycle & $\checkmark$ & - & $\checkmark$ & - \\
\hline Seo, Foliente, Ren & Australia and & Urban & Materials, Urban & Residential & Embodied \& & B & Materials and & - & $\checkmark$ & - & - \\
\hline Stephan and & Australia and & Urban & Materials, Urban & Full building stock & Embodied & B & Materials and & - & $\checkmark$ & - & - \\
\hline Zygmunt and & Europe & Regional & Retrofit & Full building stock & Embodied \& & C & Energy simulation & - & - & $\checkmark$ & - \\
\hline
\end{tabular}

occur in the reviewed studies (see Table 1). Commonly identified dynamics considered are, e.g., spatial differentiation of buildings in the stock, temporal evolution of future energy mixes, or spatial-temporal changes to buildings due to renovation activities. Some studies even anticipate the effects of climate- or weather-related changes or consider the influence of dynamic impact characterization. Other dynamic aspects considered include exogenous factors driving stock development, such as projected population development, occupational density (i.e., floor area per capita), material efficiency or the influence of financial aspects on the feasibility of certain renovation measures and related changes in the renovation rate.

We identify a need for future research on the integration of dynamic aspects, particularly in relation to background inventory (e.g. spatial and temporal differentiation of background datasets) and impact assessment (e.g. regionalisation of characterization factors or temporal dynamics of GHGs climate change impact). For foreground inventory, exogenous stock drivers, such as the influence of market-related aspects (such as real estate speculation or vacancy taxes) on construction activity, and other influences on the rate of new construction or demolition, should be integrated to assess the future impacts of stock development in different scenarios. The introduction of additional temporalities in every phase of LCA for buildings and the investigation of temporal details in socio-economic behaviour could offer added value for the modelling and monitoring of environmental impacts.

The role of dynamic aspects in the LCA of buildings is increasingly considered a key aspects to be addressed, with a recent review study by $\mathrm{Su}$ et al. investigating this very topic in more detail [44]. Beyond buildings, recent studies on dynamic LCA of mobility systems showcase the operationalization of dynamic LCA by including temporal differentiation on the complete background database [45].

\subsubsection{Stock characterization and aggregation}

We found different aggregation approaches (archetypes, building by building) applied for building stock modelling at various scales. Due to prevalent restrictions in data availability, building-by-building approaches are currently limited to building stocks at urban to national scales, which might change as more detailed building stock data (e.g., building geometry information) become more widely available. We observed that archetype-based modelling is currently the dominant approach.

We also found that larger stocks tend to have a lower ratio in the number of archetypes to the number of buildings, which raises questions about the level of detail in the modelling and should be addressed by a more refined definition of archetypes in terms of both quality and quantity. In terms of building stock characterization and clustering, we found building typology, construction year and size to be amongst the most common criteria. One way of achieving a higher level of detail is by utilizing digital building stock information tools such as GIS or BIM, which are implemented in four studies $[17,31,18,29]$ and stated as a requirement for future work in three more papers [28,29,30]' If following the predominantly applied archetype approach, further differentiation of building types -multiple variants of building layouts, e.g., for SFHs or MFHs, respectively - could enable a more representative modelling of the diversity of building layouts and occupational patterns in a given building stock.

\subsubsection{Material modelling and analysis}

Several of the existing building stock modelling studies show a fairly complete scope in terms of building parts covered; three of these are studies in a European context. At the same time, several existing studies apply multiple levels in their modelling of material-related impacts, ranging from the raw material or construction material and building element level up to the building and building cluster level. However, none of the existing studies show both a comprehensive scope in terms of the building parts covered and a high level of detail in the modelling of material-related impacts.

To date, the level of detail in both modelling and presentation of the results is limited and requires further elaboration in future research. Furthermore, spatiotemporal aspects related to embodied impacts are hardly investigated at all in current research. We found that it is mostly material-focused modelling approaches (type B) that can provide such insights and that may offer important learning opportunities for advancing the spatiotemporal modelling of environmental impacts in future building stock development if it is combined with other modelling approaches.

\subsubsection{Energy modelling and analysis}

In relation to energy modelling, the potential contribution to EU policy offered by existing approaches lies in expanding the detailed energy modelling of retrofit options to building stocks through dynamic simulation with hourly resolution, similarly to studies applying the building energy modelling-focused approach (type C).

Future research and data related to energy modelling should cover all energy end uses, consider the variation in energy demand as stock 
and climatic conditions change, consider the evolution of the energy mix and leverage the increasing availability of GIS data at the European level to characterize the building stock in greater detail.

\subsubsection{Life cycle impact assessment}

In terms of impact assessment, the studies extensively investigate climate change mitigation through the renovation of building stocks, following the main objective of the EU Green Deal to make the economy carbon neutral by 2050. All studies in our sample assess GHG-related indicators (e.g., GWP), with many focusing exclusively on these indicators.

To avoid burden shifting, all the impact categories listed in the related CEN standards should be considered, as these are relevant for the building sector. In addition, particular attention should be paid to land use impact indicators, as EU policies highlight the importance of preserving this resource. Normalization and weighting should be implemented to obtain a single indicator of environmental impact and support EU policy making in a more effective way. LCIA could be further developed to consider dynamic variation in characterization factors over time and space.

In terms of dynamics in impact assessment, existing research mostly investigates climate change and toxicity related impacts. For example, state-of-the-art modelling of climate change impacts requires to address the temporal evolution of the impacts adopting time-dependent characterization factors to assess the dynamic LCI in real-time impact scores for a given year [46]. Taking into account such dynamics has been recognized as particularly relevant for buildings, considering the multi-decades lifecycle [47,48].

\subsubsection{Interpretation of results}

Existing studies are limited in terms of the sensitivity and hotspot analyses presented. To provide relevant insights for policy makers, the hotspot analysis protocol proposed in the product environmental footprint (PEF) guidelines (EC 2013) and applied in the EU PEF4Buildings project could provide a reference for elaborating methodologies for environmental hotspot analysis at various scales.

\subsection{Insights in relation to EU policy objectives}

\subsubsection{Insights from the systematic review of scientific literature}

Table 4 presents a compilation of the strategies found in the studies and their mapping with EU policy goals. To focus the synthesis on studies in a European context, the studies are grouped by their scope $-i$. e., whether they investigate building stocks in Europe or other world regions - as well as scale and country. A detailed description of the strategies investigated in the individual studies is provided in Supplementary Information Table S8.

The analysis shows that numerous studies investigate scenarios related to the objective of energy efficiency improvement in both a European context and beyond, studying stocks at the urban up to the national and transnational scales. While most studies focus on building energy efficiency improvement based on changes to the building envelope (e.g., replacement of insulation, windows), some studies also investigate improvement of building services, such as changes to heating, cooling or ventilation systems.

The environmental implications for the objective of increasing renewable energy are investigated in several studies based on anticipated changes to the energy infrastructure, e.g., the grid electricity mix. Only one study in our sample investigated the effect of on-site renewable energy provision, e.g., through the implementation of buildingintegrated photovoltaics (BIPVs).

Low-carbon material uptake is the topic of interest in multiple studies on settings across Europe. The substitution of conventional materials with more environmentally friendly alternatives is

Table 4

Mapping of policy objectives with scenarios and strategies investigated in the reviewed literature - Overview.

\begin{tabular}{|c|c|c|}
\hline \multicolumn{3}{|c|}{ Studies investigating EU policy objectives and related aspects } \\
\hline Objectives and aspects & Europe & Non-Europe \\
\hline \multicolumn{3}{|c|}{ Improvements to energy efficiency } \\
\hline $\begin{array}{l}\text { Building energy efficiency } \\
\text { improvement }\end{array}$ & $\begin{array}{l}\text { Transnational: EU-28 [34]; Europe [25]; National: Spain [35]; } \\
\text { Switzerland [18]; Poland [19]; Urban: Luxembourg [31]; Sweden [33]; } \\
\text { Italy [37]; Portfolio: Sweden [32] }\end{array}$ & $\begin{array}{l}\text { National: New Zealand [28]; Oman/Saudi Arabia/Bahrain/United } \\
\text { Arab Emirates [20,21,26,27]; Regional: Canada [17]; Urban: } \\
\text { Australia [24] }\end{array}$ \\
\hline Building services improvement & $\begin{array}{l}\text { Transnational: Europe [25]; National: Spain [35]; Poland [19]; Urban: } \\
\text { Italy [37]; Portfolio: Sweden [32] }\end{array}$ & - \\
\hline Maintenance planning & Portfolio: Sweden [32] & - \\
\hline \multicolumn{3}{|l|}{ Increases in renewable energy } \\
\hline $\begin{array}{l}\text { Energy infrastructure (grid } \\
\text { mix) }\end{array}$ & National: Poland [19]; Sweden [23] & National: New Zealand $[16,28]$ \\
\hline On-site energy (BIPV, etc.) & National: Poland [19] & \\
\hline \multicolumn{3}{|l|}{ Low-carbon material uptake } \\
\hline $\begin{array}{l}\text { Materials: Substitution of } \\
\text { conventional materials }\end{array}$ & National: Switzerland [18]; Sweden [23]; Urban: Luxembourg [31]; & - \\
\hline $\begin{array}{l}\text { Materials: Investigating bio- } \\
\text { based material use }\end{array}$ & Transnational: EU-28 [34]; National: Sweden [23] & National: New Zealand [16] \\
\hline \multicolumn{3}{|c|}{ Climate change adaptation and resilience } \\
\hline Climate change effects & Transnational: Europe [25]; National: Sweden [23] & - \\
\hline $\begin{array}{l}\text { Intensity/speed of uptake } \\
\text { (related to policy, building } \\
\text { owners) }\end{array}$ & $\begin{array}{l}\text { Transnational: EU-28 [34]; National: Switzerland [18]; Sweden [23]; } \\
\text { Urban: Luxembourg [29,31]]; Sweden [33] }\end{array}$ & - \\
\hline Typology evolution/density & National: Sweden [23]; Switzerland [18] & - \\
\hline $\begin{array}{l}\text { Comfort/Energy simulation } \\
\text { parameters }\end{array}$ & - & National: New Zealand [28] \\
\hline $\begin{array}{l}\text { Behavioural aspects (Market/ } \\
\text { society) }\end{array}$ & National: Switzerland [18] & - \\
\hline Eco-innovation scenarios & Transnational: EU-28 [22] & - \\
\hline \multicolumn{3}{|c|}{ Monitoring of environmental performance } \\
\hline- & No studies found specifically addressing this objective & \\
\hline
\end{tabular}


investigated for building stocks at the national and urban levels. Three studies specifically investigate the increased use of bio-based materials; two of these works cover transnational (EU-28) and national building stocks in the European context.

The objective of enhancing climate change adaptation and resilience is investigated in various studies covering a wide range of scenarios. Only two studies specifically investigate the effects of climate change on building stocks in a European context. Scenarios regarding the intensity and speed of implementation of measures for both mitigation and adaptation - relating to the resilience aspect - were found for building stocks at transnational, national and urban scales in the European context. Only two studies investigate the environmental implications of the evolution of building typologies regarding density (e.g., floor area per person), based primarily on assumptions of a continued increase in this metric. One study assesses the influence of user comfort-related aspects, i.e., changes in room temperature set points, albeit not for the European context. The influence of a variety of eco-innovation scenarios in the European context is specifically investigated by Baldassarri et al. [49], building on the transnational study of Lavagna et al. [22].

No studies were found to specifically address the policy objective of monitoring environmental impacts. This represents a major research gap, as EU policy makers require comprehensive monitoring to guide the development of building stocks within environmental targets.

\subsubsection{Additional insights for the $E U$ context}

In the European context and beyond the scope of this review, some recently published studies may provide additional insights into the environmental modelling of EU building stocks. In their 2020 study, Gulotta et al. [50] present bottom-up harmonized energy-environmental models for Europe, focusing on the modelling of thermal insulation. They investigate the building stock in 28 European countries (EU-28), distinguishing three climate zones. The study uses two building typologies (SFH, MFH), adapted to represent four periods of construction and three types of geographic locations (i.e., rural, suburban and urban spatial planning contexts). Following up on a related study by Lavagna et al. [22], they advance their model to include dynamic energy simulation and, again, investigate a comprehensive set of environmental indicators. A recent study by Göswein et al. [51] investigates the implication of increased land use requirements from a radical shift to bio-based materials for new construction in Europe. An investigation of global scenarios for material efficiency in buildings, including the modelling of related emission reduction potentials for several European countries, are forthcoming by Pauliuk et al. [52].

\subsection{Future research and data needs}

To further advance the environmental modelling of building stocks and, in particular, to support EU policy making, various research and data gaps need to be addressed. As outlined in this study, existing approaches offer various types of potential in their individual modelling aspects and should be combined to provide the added value of both comprehensive and highly detailed building stock models.

Data gaps need to be addressed specifically regarding data on building stock composition and geometric parameters at scales beyond the urban and national level to support, e.g., building-by-building modelling of the whole EU building stock. To advance the prevailing archetype-based modelling, the quality and quantity of archetypes used to represent building stocks should be boosted to provide more nuanced and representative assessments. Building on European projects such as TABULA and EPISCOPE and using centrally curated building stock data such as those provided by the EU Building Stock Observatory can enable more detailed modelling while maintaining a harmonized approach to archetype definition. Furthermore, potentially useful data on the environmental modelling of buildings may be obtained from related research collaborations such as IEA EBC Annex 57 (on embodied energy and GHG emissions of buildings) and the ongoing IEA EBC Annex 72 (on comprehensive LCA for buildings across the full life cycle) or the recently started IEA EBC Annex 75 (on building renovation at the district level).

A particular research gap identified in this work is the lack of studies monitoring the environmental impacts of building stock development in relation to the environmental targets outlined by EU policy. This research gap must be addressed to enable active development of the EU building stock within environmental boundaries. In this regard, environmental benchmark data for EU buildings are lacking in terms of both existing building performance (baseline) and target values. Ongoing initiatives such as the EU Level(s) project may provide crucial insights into the performance of new buildings, which might benefit from recent research findings on building life cycle performance [7] and environmental benchmarks [53] and targets for buildings [6]. Concerning environmental targets for buildings and their implementation, EU policy, standards and regulations, such as the Construction Products Regulation (CPR), will play a key role.

Furthermore, improved links to other research fields in the domain of ecosystem management may be relevant to ensure clear system boundaries and to avoid double counting, particularly considering the increased interest in using buildings as carbon sinks [54] through the increased use of bio-based materials and related challenges of biogenic carbon modelling [55].

\section{Conclusion and outlook}

Our study presents an integrated assessment of scientific developments in the environmental modelling of buildings and policy objectives related to the buildings and construction sector. Through a systematic literature review and analysis, we evaluated the state of the art of environmental modelling of building stocks and spatiotemporal dynamics related to their future development. Based on the assessment of more than 100 studies, 22 were shortlisted for a comprehensive analysis. Analysing the studies from a life cycle assessment perspective, we investigated each study in the context of its goal and scope, consideration of dynamics and scenario variables, modelling and analysis of building stock characterization and aggregation, and materialand energy-related environmental impacts. We analysed the LCA methodology in terms of LCA scenarios, impact assessment methods and environmental indicators as well as the interpretation of results. Furthermore, we categorized existing methodological approaches and discussed the individual characteristics, strengths and weaknesses of approaches focusing on a product life cycle perspective, modelling of material-related impacts, building energy simulation, and the added value of assessing financial cost-related aspects.

We find that existing studies vary strongly in terms of their spatiotemporal scope at both the building stock and building level, with studies ranging from the portfolio and urban scales up to the national and transnational scales and conducting (mostly prospective) analyses with a timeframe from one or a few years up to 200 years. Our analysis of existing building stock modelling approaches provides relevant insights in terms of modelling material- and energy-related impacts but also reveals a research gap and lack of studies featuring both a comprehensive scope and a high level of detail. Furthermore, the environmental indicators covered in existing studies are very limited, with most studies focusing exclusively on GHG-related indicators. To fully comprehend environmental impacts and avoid burden shifting, all impact categories listed in recent CEN standards for environmental impact assessment of buildings should be considered.

Environmental hotspot analyses at the level of building clusters and individual buildings are scarcely found at all in the current literature, with a complete lack of studies providing such analyses at the level of detail suggested in recent EU-related documents such as the EF guidelines.

Most studies in our final sample focus their analyses on operational energy and the environmental implications of retrofitting the existing 
building stock. Although the EU policy objective of improving the energy efficiency of the stock is widely taken into account by existing models, further research developments should focus on the monitoring over time of environmental impacts related to all energy end uses in households. For this purpose, variations in climatic conditions and the energy mix should be considered. Few studies investigate the environmental implications of new construction activity that will take place in the coming decades. Finally, we identified a total lack of studies investigating how to monitor and actively guide EU building stock development in alignment with environmental targets and identified this as an important area for future research.

\section{Data availability}

The data presented and discussed in this paper are available as supplementary data (.XLS). We encourage readers to check the supplementary data for detailed insights on each of the studies in this review.

\section{CRediT author statement}

Martin Röck: Conceptualization; methodology; formal analysis; investigation; data curation and visualization; writing - original draft; writing - review and editing; project administration. Elena Baldereschi: Methodology; formal analysis; investigation; writing - original draft. Evelien Verellen: Formal analysis; investigation; visualization; writing - original draft. Alexander Passer: Conceptualization; writing review and editing; supervision. Serenella Sala: Conceptualization; writing - review and editing; supervision. Karen Allacker: Conceptualization; methodology; writing - review and editing; supervision.

\section{Funding and acknowledgements}

Martin Röck is a dual PhD candidate at KU Leuven and TU Graz and received funding through a DOC Fellowship of the Austrian Academy of Sciences (OeAW) [2019/1]. Elena Baldereschi contributed to this work in the context of the Collaborative Doctoral Partnership programme launched by the European Commission Joint Research Centre to promote research at the interface of science and policy. Alexander Passer contributed in context of the ParisBuildings project, which is financially supported by the Klima- und Energiefonds, Austrian Climate Research Programme (ACRP) [ACRP11 KR18AC0K14693].

\section{Declaration of competing interest}

The authors declare that they have no known competing financial interests or personal relationships that could have appeared to influence the work reported in this paper.

\section{Appendix A. Table of policy documents}

\begin{tabular}{|c|c|}
\hline Name & Reference \\
\hline Better Regulation Toolbox & $\begin{array}{l}\text { EC, COM(2021)219 Communication from the Commission to the European Parliament, the Council, the European Economic and Social Committee } \\
\text { and the Committee of the Regions. Better regulation: Joining forces to make better law. } \\
\text { EC, COM(2015)215, Communication from the Commission to the European Parliament, the Council, the European Economic and Social Committee } \\
\text { and the Committee of the Region. Better Regulation for better results - An EU agenda. }\end{array}$ \\
\hline $\begin{array}{l}\text { Europe's } 2030 \text { Climate } \\
\text { Ambition }\end{array}$ & EC, COM(2020)562, Stepping up Europe's 2030 climate ambition - Investing in a climate-neutral future for the benefit of our people. \\
\hline European Green Deal & EC, COM(2019)640, The European Green Deal, incl. Annex. \\
\hline $\begin{array}{l}\text { Circular Economy Action } \\
\text { Plan }\end{array}$ & EC, COM(2020)98, A new Circular Economy Action Plan - For a cleaner and more competitive Europe, incl. Annex. \\
\hline $\begin{array}{l}\text { Biodiversity Strategy for } \\
2030\end{array}$ & EC, COM(2020)380, EU Biodiversity Strategy for 2030 - Bringing nature back into our lives, incl. Annex. \\
\hline European Climate Law & $\begin{array}{l}\text { EC, } \operatorname{COM}(2020) 80 \text {, Proposal for (...) establishing the framework for achieving climate neutrality and amending Regulation (EU) } 2018 / 1999 \\
\text { (European Climate Law). }\end{array}$ \\
\hline Renovation Wave for Europe & EC, COM(2020)662, A Renovation Wave for Europe - greening our buildings, creating jobs, improving lives. \\
\hline A Clean Planet for All & $\begin{array}{l}\text { EC, } \operatorname{COM}(2018) 773 \text {, A Clean Planet for all - A European strategic long-term vision for a prosperous, modern, competitive and climate neutral economy, } \\
2018 .\end{array}$ \\
\hline Bioeconomy Strategy & $\begin{array}{l}\text { EC, COM(2018)673/2 and SWD (2018)431/2, A sustainable Bioeconomy for Europe: strengthening the connection between economy, society and the } \\
\text { environment. }\end{array}$ \\
\hline New Industrial Strategy & EC, COM(2020)102, A New Industrial Strategy for Europe. \\
\hline EU SDGs & EC, COM(2019)22, Towards a sustainable Europe by 2030. \\
\hline Waste Framework Directive & EC, COM(2015)595, Proposal for a Directive of the European Parliament and the Council amending Directive 2008/98/EC on waste, incl. Annex. \\
\hline
\end{tabular}

Table of standards and regulations.

\begin{tabular}{|c|c|}
\hline Name & Reference \\
\hline $\begin{array}{l}\text { ISO } \\
14044\end{array}$ & $\begin{array}{l}\text { International Organization for Standardization (ISO). ISO 14044, Environmental management - Life cycle assessment - Requirements and guidelines (ISO 14044:2006) } \\
2006 .\end{array}$ \\
\hline EN 15804 & $\begin{array}{l}\text { European Committee for Standardization (CEN), CEN/TC 350. EN 15804:2012-A2:2019 - Sustainability of construction works - Environmental product declarations - } \\
\text { Core rules for the product category of construction. } 2019 .\end{array}$ \\
\hline EN 15978 & $\begin{array}{l}\text { European Committee for Standardization (CEN), CEN/TC 350. EN } 15978 \text { - Sustainability of construction works - Assessment of environmental performance of buildings } \\
\text { - Calculation method. } 2011 \text {. }\end{array}$ \\
\hline
\end{tabular}

Table of environmental footprint (EF) guidelines.

\begin{tabular}{|c|c|}
\hline Name & Reference \\
\hline $\begin{array}{l}\text { EC } \\
(2013 a)\end{array}$ & $\begin{array}{l}\text { Communication from the Commission to the European Parliament and the Council - Building the Single Market for Green Products - Facilitating better information on } \\
\text { the environmental performance of products and organisations. } \operatorname{COM}(2013) 196\end{array}$ \\
\hline $\begin{array}{l}\text { EC } \\
(2013 b)\end{array}$ & $\begin{array}{l}\text { Recommendation 2013/179/EU on the use of common methods to measure and communicate the life cycle environmental performance of products and organisations, } \\
\text { Annex III, OJ L 124, May 4, 2013, p. 1-210. Available at: https://eur-lex.europa.eu/legal-content/EN/TXT/?uri=CELEX\%3A32013H0179 }\end{array}$ \\
\hline \multicolumn{2}{|r|}{$\begin{array}{l}\text { Further information on the EF and related documents can be found online via the European Platform on Life Cycle Assessment: https://eplca.jrc.ec.europa.eu/EnvironmentalFootprint. } \\
\text { html. }\end{array}$} \\
\hline
\end{tabular}




\section{Appendix B. Supplementary data}

Supplementary data (.XLS) to this article can be found online at https://doi.org/10.1016/j.rser.2021.111550. Additional information on the methods and results is provided in the supplementary information (.DOC).

\section{References}

[1] Sala S, Benini L, Crenna E, Secchi M. Global environmental impacts and planetary boundaries in LCA. 2016. https://doi.org/10.2788/64552.

[2] Steffen W, Rockström J, Richardson K, Lenton TM, Folke C, Liverman D, et al. Trajectories of the earth system in the anthropocene. Proc Natl Acad Sci Unit States Am 2018;115:8252-9. https://doi.org/10.1073/pnas.1810141115.

[3] Global Alliance for Buildings and Construction (GABC). International energy agency (IEA), united nations environment programme (UNEP). 2019 Global Status Report for Buildings and Construction 2019.

[4] Ivanova D, Vita G, Steen-Olsen K, Stadler K, Melo PC, Wood R, et al. Mapping the carbon footprint of EU regions. Environ Res Lett 2017:12. https://doi.org/ 10.1088/1748-9326/aa6da9.

[5] Sala S, Castellani V. The consumer footprint: monitoring sustainable development goal 12 with process-based life cycle assessment. J Clean Prod 2019;240:118050. https://doi.org/10.1016/j.jclepro.2019.118050.

[6] Habert G, Röck M, Steininger K, Lupisek A, Birgisdottir H, Desing H, et al. Carbon budgets for buildings: harmonizing temporal, spatial and sectoral dimensions. Build Cities 2020:1-24. https://doi.org/10.5334/bc.47.

[7] Röck M, Ruschi Mendes Saade M, Balouktsi M, Nygaard F, Birgisdottir H, Frischknecht R, et al. Embodied GHG emissions of buildings - the hidden challenge for effective climate change mitigation. Appl Energy 2020. https://doi.org/ 10.1016/j.apenergy.2019.114107.

[8] International Energy Agency (IEA). Transition to sustainable buildings - strategies and opportunities to 2050. 2013. https://doi.org/10.1787/9789264202955-en.

[9] Sala S, Martino A, Antoine A, Fulvio B. The evolution of life cycle assessment in European policies over three decades. Int J Life Cycle Assess 2021. https://doi.org/ 10.1007/s11367-021-01893-2.

[10] Sala S, Reale F, Cristobal-Garcia J, Marelli L, Pant R. Life cycle assessment for the impact assessment of policies - life thinking and assessment in the European policies and for evaluating policy options. https://doi.org/10.2788/318544; 2016.

[11] Moffatt S. Stock aggregation - methods for evaluating the environmental performance of building stocks - IEA ECBCS Annex 31-energy-related environmental impact of buildings. 2004. p. 30.

[12] Mastrucci A, Marvuglia A, Leopold U, Benetto E. Life Cycle Assessment of building stocks from urban to transnational scales: a review. Renew Sustain Energy Rev 2017;74:316-32. https://doi.org/10.1016/j.rser.2017.02.060.

[13] Göswein V, Silvestre J, Habert G, Freire F. Dynamic assessment of construction materials in urban building stocks - a critical review. Environ Sci Technol 2019. https://doi.org/10.1021/acs.est.9b01952. acs.est.9b01952.

[14] Haddaway NR, Bethel A, Dicks LV, Koricheva J, Macura B, Petrokofsky G, et al. Eight problems with literature reviews and how to fix them. Nat Ecol Evol 2020. https://doi.org/10.1038/s41559-020-01295-x.

[15] Higgins JP, Green S. Cochrane handbook for systematic reviews of interventions. Cochrane Book Series. vol. Version 5 2008. https://doi.org/10.1002/ 9780470712184.

[16] Chandrakumar C, McLaren SJ, Dowdell D, Jaques R. A science-based approach to setting climate targets for buildings: the case of a New Zealand detached house. Build Environ 2020;169:106560. https://doi.org/10.1016/j. buildenv.2019.106560.

[17] Feng H, Liyanage DR, Karunathilake H, Sadiq R, Hewage K. BIM-based life cycle environmental performance assessment of single-family houses: renovation and reconstruction strategies for aging building stock in British Columbia. J Clean Prod 2020;250:119543. https://doi.org/10.1016/j.jclepro.2019.119543.

[18] Heeren N, Hellweg S. Tracking construction material over space and time: prospective and geo-referenced modeling of building stocks and construction material flows. J Ind Ecol 2019;23:253-67. https://doi.org/10.1111/jiec.12739.

[19] Zygmunt M, Piczulski M. Economic, environmental and social aspects of buildings refurbishment - a case study. Sci Rev Eng Environ Sci 2018;2019(27):567-78. https://doi.org/10.22630/PNIKS. 27.4.52.

[20] Krarti M, Dubey K. Benefits of energy efficiency programs for residential buildings in Bahrain. J Build Eng 2018;18:40-50. https://doi.org/10.1016/j. jobe.2018.02.018.

[21] Krarti M, Dubey K. Review analysis of economic and environmental benefits of improving energy efficiency for UAE building stock. Renew Sustain Energy Rev 2018;82:14-24. https://doi.org/10.1016/j.rser.2017.09.013.

[22] Lavagna M, Baldassarri C, Campioli A, Giorgi S, Dalla Valle A, Castellani V, et al. Benchmarks for environmental impact of housing in Europe: definition of archetypes and LCA of the residential building stock. Build Environ 2018;145: 260-75. https://doi.org/10.1016/j.buildenv.2018.09.008.

[23] Peñaloza D, Erlandsson M, Berlin J, Wålinder M, Falk A. Future scenarios for climate mitigation of new construction in Sweden: effects of different technological pathways. J Clean Prod 2018;187:1025-35. https://doi.org/10.1016/j. jclepro.2018.03.285.

[24] Seo S, Foliente G, Ren Z. Energy and GHG reductions considering embodied impacts of retrofitting existing dwelling stock in Greater Melbourne. J Clean Prod 2018;170:1288-304. https://doi.org/10.1016/j.jclepro.2017.09.206.
[25] Almeida M, Ferreira M. Cost effective energy and carbon emissions optimization in building renovation (Annex 56). Energy Build 2017;152:718-38. https://doi.org/ 10.1016/j.enbuild.2017.07.050.

[26] Krarti M, Dubey K, Howarth N. Evaluation of building energy efficiency investment options for the Kingdom of Saudi Arabia. Energy 2017;134:595-610. https://doi. org/10.1016/j.energy.2017.05.084.

[27] Krarti M, Dubey K. Energy productivity evaluation of large scale building energy efficiency programs for Oman. Sustain Cities Soc 2017;29:12-22. https://doi.org/ 10.1016/j.scs.2016.11.009.

[28] Ghose A, McLaren SJ, Dowdell D. Upgrading New Zealand's existing office buildings - an assessment of life cycle impacts and its influence on 2050 climate change mitigation target. Sustain Cities Soc 2020;57:102134. https://doi.org/ 10.1016/j.scs.2020.102134.

[29] Mastrucci A, Marvuglia A, Popovici E, Leopold U, Benetto E. Geospatial characterization of building material stocks for the life cycle assessment of end-oflife scenarios at the urban scale. Resour Conserv Recycl 2017;123:54-66. https:// doi.org/10.1016/j.resconrec.2016.07.003.

[30] Stephan A, Athanassiadis A. Quantifying and mapping embodied environmental requirements of urban building stocks. Build Environ 2017;114:187-202. https:// doi.org/10.1016/j.buildenv.2016.11.043.

[31] Mastrucci A, Marvuglia A, Benetto E, Leopold U. A spatio-temporal life cycle assessment framework for building renovation scenarios at the urban scale. Renew Sustain Energy Rev 2020;109834:126. https://doi.org/10.1016/j. rser.2020.109834.

[32] Nägeli C, Farahani A, Österbring M, Dalenbäck J-O, Wallbaum H. A service-life cycle approach to maintenance and energy retrofit planning for building portfolios. Build Environ 2019;106212:160. https://doi.org/10.1016/j. buildenv.2019.106212.

[33] Österbring M, Mata É Thuvander L, Wallbaum H. Explorative life-cycle assessment of renovating existing urban housing-stocks. Build Environ 2019;106391:165. https://doi.org/10.1016/j.buildenv.2019.106391.

[34] Pittau F, Lumia G, Heeren N, Iannaccone G, Habert G. Retrofit as a carbon sink: the carbon storage potentials of the EU housing stock. J Clean Prod 2019;214:365-76. https://doi.org/10.1016/j.jclepro.2018.12.304.

[35] Pombo O, Rivela B, Neila J. Life cycle thinking toward sustainable development policy-making: the case of energy retrofits. J Clean Prod 2019;206:267-81. https://doi.org/10.1016/j.jclepro.2018.09.173.

[36] Drouilles J, Aguacil S, Hoxha E, Jusselme T, Lufkin S, Rey E. Environmental impact assessment of Swiss residential archetypes: a comparison of construction and mobility scenarios. Energy Effic 2019;12:1661-89. https://doi.org/10.1007/ s12053-019-09811-0.

[37] Gabrielli L, Ruggeri AG. Developing a model for energy retrofit in large building portfolios: energy assessment, optimization and uncertainty. Energy Build 2019; 202:109356. https://doi.org/10.1016/j.enbuild.2019.109356.

[38] Heeren N, Jakob M, Martius G, Gross N, Wallbaum H. A component based bottomup building stock model for comprehensive environmental impact assessment and target control. Renew Sustain Energy Rev 2013;20:45-56. https://doi.org/ 10.1016/j.rser.2012.11.064.

[39] Trigaux D, Allacker K, De Troyer F. Model for the environmental impact assessment of neighbourhoods. WIT Trans Ecol Environ 2014;181:103-14. https://doi.org/ 10.2495/EID140091.

[40] Spirinckx C, Thuring M, Damen L, Allacker K, Ramon D, Mirabella N, et al. Testing of PEF method to assess the environmental footprint of buildings - results of PEF4Buildings project. IOP Conf. Ser. Earth Environ. Sci. 2019;297. https://doi. org/10.1088/1755-1315/297/1/012033.

[41] Krarti M, Dubey K. Review analysis of economic and environmental benefits of improving energy efficiency for UAE building stock. Renew Sustain Energy Rev 2018;82:14-24. https://doi.org/10.1016/j.rser.2017.09.013.

[42] Ghose A, Pizzol M, McLaren SJ, Vignes M, Dowdell D. Refurbishment of office buildings in New Zealand: identifying priorities for reducing environmental impacts. Int J Life Cycle Assess 2019;24:1480-95. https://doi.org/10.1007/ s11367-018-1570-5.

[43] Allacker K, Castellani V, Baldinelli G, Bianchi F, Baldassarri C, Sala S. Energy simulation and LCA for macro-scale analysis of eco-innovations in the housing stock. Int J Life Cycle Assess 2019;24:989-1008. https://doi.org/10.1007/s11367018-1548-3.

[44] Su S, Zhang H, Zuo J, Li X, Yuan J. Assessment models and dynamic variables for dynamic life cycle assessment of buildings: a review. Environ Sci Pollut Res 2021: 26199-214. https://doi.org/10.1007/s11356-021-13614-1.

[45] Pigné Y, Gutiérrez TN, Gibon T, Schaubroeck T, Popovici E, Shimako AH, et al. A tool to operationalize dynamic LCA, including time differentiation on the complete background database. Int J Life Cycle Assess 2020;25:267-79. https://doi.org/ 10.1007/s11367-019-01696-6.

[46] Levasseur A, Lesage P, Margni M, Deschěnes L, Samson R. Considering time in LCA: dynamic LCA and its application to global warming impact assessments. Environ Sci Technol 2010;44:3169-74. https://doi.org/10.1021/es9030003. 
[47] Negishi K, Tiruta-Barna L, Schiopu N, Lebert A, Chevalier J. An operational methodology for applying dynamic Life Cycle Assessment to buildings. Build Environ 2018;144:611-21. https://doi.org/10.1016/j.buildenv.2018.09.005.

[48] Negishi K, Lebert A, Almeida D, Chevalier J, Tiruta-Barna L. Evaluating climate change pathways through a building's lifecycle based on Dynamic Life Cycle Assessment. Build Environ 2019;164:106377. https://doi.org/10.1016/j. buildenv.2019.106377.

[49] Baldassarri C, Allacker K, Reale F, Castellani V, Sala S. Consumer footprint: basket of products indicator on housing. 2017. https://doi.org/10.2760/05316.

[50] Gulotta TM, Cellura M, Guarino F, Longo S. A bottom-up harmonized energyenvironmental models for europe (BOHEEME): a case study on the thermal insulation of the EU-28 building stock. Energy Build 2020:110584. https://doi. org/10.1016/j.enbuild.2020.110584.
[51] Göswein V, Reichmann J, Habert G, Pittau F. Land availability in Europe for a radical shift toward bio-based construction. Sustain Cities Soc 2021:70. https:// doi.org/10.1016/j.scs.2021.102929.

[52] Pauliuk S, Heeren N, Haven N, States U, Berrill P. Global scenarios of resource and emissions savings from systemic material eciency in buildings and cars n.d.:1-18.

[53] Trigaux D, Allacker K, Debacker W. Environmental benchmarks for buildings: a critical literature review. Int J Life Cycle Assess 2021;26:1-21. https://doi.org/ 10.1007/s11367-020-01840-7.

[54] Churkina G, Organschi A, Reyer CPO, Ruff A, Vinke K, Liu Z, et al. Buildings as a global carbon sink. Nat Sustain 2020. https://doi.org/10.1038/s41893-019-0462-

[55] Hoxha E, Passer A, Saade MRM, Trigaux D, Shuttleworth A, Pittau F, et al. Biogenic carbon in buildings: a critical overview of LCA methods. Build Cities 2020;1: 504-24. https://doi.org/10.5334/bc. 46. 